\title{
OTIMIZAÇÃO DO GASTO PÚBLICO NOS MUNICÍPIOS BRASILEIROS
}

André Luiz Marques Serrano'

Layane Gonçalves Furtado2

Lucas Oliveira Gomes Ferreira ${ }^{3}$

- Artigo recebido em: 10/04/2020 -- Artigo aceito em: 30/05/2020 -.- Segunda versão aceita em: 09/07/2020

\section{RESUMO}

O objetivo deste trabalho é analisar a influência da composição dos gastos públicos municipais na promoção do crescimento econômico, pois a classificação da função dos gastos permite avaliar o perfil do município frente ao crescimento econômico. Para tanto, o estudo analisa 5.533 municípios brasileiros no período de 2001 a 2016. Com o intuito de examinar a produtividade lou improdutividade) dos gastos públicos por função municipal em relação ao crescimento econômico, os modelos empíricos se fundamentam no modelo teórico de Devarajan, Swaroop e Zou (1996). Todos os modelos foram estimados pelo modelo de efeitos fixos. Os resultados indicam que, nos municípios desenvolvidos, foram produtivos os gastos com habitação e urbanismo e com energia, e foram improdutivos os gastos com a função legislativa. Nos municípios não desenvolvidos, os gastos com transportes foram produtivos, enquanto os gastos com as funções judiciária e saúde foram improdutivos. Como análise adicional, examinou-se uma relação teórica não-linear dos gastos públicos com o crescimento econômico. Nos municípios não desenvolvidos, inferiu-se uma relação não linear dos gastos com as funções judiciária e educação e cultura. Nos desenvolvidos, inferiu-se uma relação não linear dos gastos com as funções legislativa e saúde e saneamento. Os resultados desta pesquisa corroboram as evidências apontadas no modelo teórico fundamentado. Diante desses resultados, sugere-se realocação na composição dos gastos públicos municipais brasileiros com o objetivo de alcançar uma maximização da contribuição de cada gasto no crescimento econômico.

1 Doutor em Economia pela Universidade de Brasília - UnB. Professor Associado do Departamento de Engenharia de Produção da UnB. Endereço: Campus Universitário Darcy Ribeiro, Asa Norte, Brasília-DF, Brasil, CEP 70910-900. Telefone: (61) 3107-0795. E-mail: andrelms@unb.br.

https://orcid.org/0000-0001-5182-0496

2 Mestre em Ciências Contábeis pelo Programa de Pós-Graduação em Ciências Contábeis da Universidade de Brasília. Endereço: Campus Universitário Darcy Ribeiro, Asa Norte, BrasíliaDF, Brasil, CEP 70910-900. Telefone: (61) 3107-0795. E-mail: andrelms@unb.br.

3 Doutorando em Ciências Contábeis pelo Programa de Pós-Graduação em Ciências Contábeis da Universidade de Brasília - UnB. Professor Adjunto do Departamento de Ciências Contábeis e Atuariais da UnB. Endereço: Campus Universitário Darcy Ribeiro, Asa Norte, Brasília-DF, Brasil, CEP 70910-900. Telefone: (61) 3107-0795. E-mail: lucasoliveira@unb.br. https://orcid.org/0000-0002-8734-4740

Editor responsável pela aprovação do artigo: Dr. João Estevão Barbosa Neto Editora responsável pela edição do artigo: Dr ${ }^{\mathrm{a}}$. Bruna Camargos Avelino 
Palavras-Chave: Realocação. Gasto Público. Crescimento Econômico. Municípios.

\section{OPTIMIZATION OF PUBLIC SPENDING IN BRAZILIAN MUNICIPALITIES}

\section{ABSTRACT}

The objective of this study is to analyze the influence of the composition of municipal public expenditure in the promotion of economic growth, from 2001 to 2016. For this, the study analyzes 5,533 Brazilian municipalities. In order to examine the productivity (or unproductivity) of municipal public expenditure by function in relation to economic growth, the empirical models are based on the theoretical model of Devarajan, Swaroop and Zou (1996). All models were estimated by the fixed effects model. The results indicate that, in the three models analyzed (all municipalities, developed municipalities and undeveloped municipalities), the productivity of public expenditure was lower than the deadweight loss associated with the taxes required to fincance it. Beyond that, the results indicate that, in the developed municipalities, housing and urbanism expenditure and energy expenditure were productive, while legislative expenditure was unproductive. In the undeveloped municipalities, transport expenditure was productive, while judicial expenditure and health expenditure were unproductive. As an additional analysis, a nonlinear theoretical relationship of public expenditure to economic growth was analyzed. In underdeveloped municipalities, it is inferred a non-linear relationship in judicial expenditure and in education and culture expenditure. In developed municipalities, it is inferred a non-linear relationship in legislative expenditure and health and sanitation expenditure.

Keywords: Reallocation. Public Expenditure. Economic Growth. Municipalities.

\section{INTRODUÇÃO}

Em virtude do atual contexto econômico brasileiro, é possível observar que se desenvolve um debate sobre os rumos e as propostas das políticas fiscais capazes de promover a solvência do setor público e a estabilidade da dívida pública. A motivação principal decorre dos resultados fiscais insatisfatórios e da trajetória ascendente da dívida pública nos últimos anos (Cardoso et al., 2018).

Para controlar a evolução da relação Dívida Pública/Produto Interno Bruto (PIB) e da deterioração das contas públicas federais, destaca-se a promulgação da Lei de Responsabilidade Fiscal (LRF), que limitou despesas e endividamento. Outro destaque é a aprovação da Emenda Constitucional no 95/2016, cujos principais objetivos é reduzir a instabilidade econômica brasileira por meio da adoção de limites individualizados para as despesas primárias federais por até vinte anos. Adicionalmente, destaca-se a discussão da reforma previdenciária, como forma de combater os desequilíbrios fiscais decorrentes da pressão do déficit previdenciário e de se contrapor às tendências demográficas brasileiras das próximas décadas (Giambiagi \& Sidone, 2018).

Nesse cenário, exigem-se cada vez mais tomadas de decisões que impliquem redução e alocação mais produtiva dos gastos públicos brasileiros, 
pois são recursos consumidos pelas ações estratégicas governamentais, registrados no orçamento público, e que, portanto, constituem instrumentos governamentais de política fiscal (Araújo, Monteiro \& Cavalcante, 2010; Giuberti \& Rocha, 2015; Neduziak \& Correia, 2017).

Na tomada de tais decisões, diversas questões emergem: É possível a promoção de crescimento econômico, mesmo quando altos níveis de endividamento público impedem o governo de aumentar o nível de gastos públicos durante vários anos? É possível promover crescimento econômico com a realocação de componentes do gasto público? Em virtude do envelhecimento da população brasileira e o consequente aumento de gastos com saúde e proteção social, é possível decidir quais gastos devem ser priorizados nas próximas décadas?

A expressiva participação pública na economia mantém, no campo das finanças públicas, vívido o debate sobre essas questões suscitadas. Em síntese, tanto o gasto público, quanto o crescimento econômico, são relevantes à tomada de decisão, pois a análise interpretativa de suas variáveis evidencia a produtividade de uma política fiscal sobre o crescimento econômico, possibilitando decisões capazes de contribuir com uma gestão e alocação mais produtiva de recursos públicos (Araújo, Monteiro \& Cavalcante, 2010; Giuberti \& Rocha, 2015; Sousa \& Paulo, 2016; Neduziak \& Correia, 2017).

Diversos estudos analisaram os impactos da política fiscal sobre o crescimento econômico a partir de uma análise de produtividade da alocação dos recursos públicos em relação ao crescimento (Aschaver, 1989; Barro, 1990; Cândido Júnior, 2001; Souza, 2007; Rocha \& Giuberti, 2007; Souza et al., 2010; Divino \& Silva Júnior, 2012; Sousa \& Paulo, 2016; Neduziak \& Correia, 2017; Lupu, 2018; Yilmaz, 2018).

Desse modo, este estudo propõe a análise da seguinte questão central: Como a composição dos gastos públicos dos municípios brasileiros, a partir da classificação funcional da despesa pública, promove crescimento econômico? A partir desta questão, emerge a suposição defendida neste estudo, a qual considera a possibilidade de promoção do crescimento econômico por meio da realocação de gastos públicos municipais (sem aumento do nível de gastos).

Destarte, tal realocação pode se configurar como uma alavanca econômica capaz de influenciar o atual ambiente brasileiro de baixo crescimento. Ademais, considera-se a possibilidade de auxiliar na tomada de decisão no que se refere a cortes ou diminuições de gastos nas próximas décadas, ao evidenciar a composição dos gastos públicos e destacar aqueles improdutivos. Além dessa introdução, esse estudo apresenta o referencial teórico na Seção 2; os procedimentos metodológicos na Seção 3; os resultados na Seção 4 e as considerações finais na Seção 5.

\section{REFERENCIAL TEÓRICO}

Inicialmente, os conceitos de produtividade e crescimento econômico são básicos nesse contexto. Produtividade é definida como a relação entre produtos e insumos (Farrel, 1957). Quanto mais produtos forem realizados com a utilização de determinada quantidade de insumo, mais produtivo ele é (Lovell, 1993). No âmbito do setor público, produtivididade tem o mesmo sentido, sendo o gasto 
público produtivo aquele que mais produtos são entregues à sociedade com a utilização de determinados insumos. Em outras palavras, gasto público produtivo é aquele que, na função de produtividade do setor privado, tem efeito direto na taxa de crescimento. Há evidências empíricas de que os gastos com defesa, educação, saúde, habitação, transporte, energia e comunicação são classificados como produtivos (Aschaver, 1989, Barro, 1991, Kneller, Bleaney e Gemmell, 1999, Bleaney, Gemmell e Kneller, 2001, e Bayraktar e Moreno-Dodson, 2010). Há evidências também de que com a elevação da produtividade do setor privado, os gastos públicos conseguem elevar o crescimento econômico (Ram, 1986, Cashin, 1995).

Embora o conceito de crescimento econômico seja controverso nas ciências sociais (Scatolin, 1989), o presente trabalho considera seu conceito no sentido estrito de aumento de renda per capita, ou basicamente variação quantitativa do produto (Harrod, 1972, Domar, 1946, Schumpeter, 1961).

Os estudos sobre a relação entre os gastos públicos e o crescimento econômico se alavancaram no início de 1990, a partir do estudo seminal de Barro (1990) sobre modelo de crescimento endógeno e gastos públicos. No entanto, o ponto de partida desta linha de pesquisa foi Aschaver (1989) que, em um dos primeiros trabalhos sobre a produtividade dos gastos públicos, descobriu que o investimento público é um preditor significativo da produtividade desse tipo de gasto em relação ao crescimento econômico dos Estados Unidos, no período entre 1949 e 1985.

Apesar de algumas revisões críticas (Gramlich, 1994), os achados de Aschaver, a respeito da economia norte-americana, foram confirmados por outros autores (Heintz, 2010). Ademais, em estudos mais recentes em outros países, também é possível observar o impacto econômico positivo a partir de investimento público, tais como na Turquia (Yilmaz, 2018), na Colômbia (Campo \& Mendoza, 2018), no Zimbábue (Makuyana \& Odhiambo, 2017) e em Camarões (Ntembe, Amin \& Tawah, 2017).

Em geral, pode-se segregar a literatura que analisa a relação entre a composição das despesas administrativas e crescimento econômico em dois principais grupos. Os que investigam a composição do gasto público desagregando-o como gasto de capital e corrente (Barro, 1991; Devarajan et al., 1996; Bose, Haque \& Osborn, 2007; Ghosh \& Gregoriou, 2008), e os que enfocam a composição funcional dos gastos públicos como saúde, educação e infraestrutura (Bose, Haque \& Osborn, 2007; Kneller \& Misch, 2014; Makuyana \& Odhiambo, 2017; Ntembe, Amin \& Tawah, 2017; Lupu, 2018; Campo \& Mendoza, 2018; Yilmaz, 2018).

Em termos empíricos, essa relação é evidenciada em diversos resultados encontrados pelas pesquisas ao longo do tempo. Barro (1990), ao estender a estrutura de crescimento endógeno, incluiu serviços governamentais financiados, concluindo que, quando a parcela das despesas do governo é baixa, os gastos do governo são positivamente ligados ao crescimento econômico.

Na sequência de seus estudos, Barro (1991) observou que não ocorreu a ligação esperada entre os gastos públicos e o crescimento econômico quando - consumo do governo era negativamente relacionado ao crescimento econômico. Gastos com despesas de consumo não teriam efeito direto na produtividade do capital privado, pois reduziriam a poupança e o crescimento 
através de efeitos distorcidos na tributação e nos gastos em programas de governo.

Por outro lado, Devarajan et al. (1996) e Ghosh e Gregoriou (2008) verificaram que, em países em desenvolvimento, o gasto corrente era positivo e significativamente associado com o crescimento. Enquanto, os resultados de Bose, Haque e Osborn (2007) indicaram que o efeito das despesas correntes era insignificante.

Devarajan et al. (1996) também observaram que aumento em gastos de capital tem efeito negativo no crescimento econômico. Este resultado inesperado evidenciou que gastos aparentemente produtivos, tais como investimentos públicos, quando usados em excesso, podem se tornar improdutivos. Evidência também constatada por Fournier e Johansson (2016), ao analisarem países da Organização para a Cooperação e Desenvolvimento Econômico (OCDE). Por outra perspectiva, Kneller e Misch (2014) perceberam que investimento em infraestrutura poderia melhorar a produtividade das empresas, visto que esse tipo de investimento facilitaria o acesso a um maior número de fornecedores.

Assim, ao revisar a literatura, observa-se que a análise empírica da relação entre os gastos públicos e o crescimento econômico compreende uma diversidade de abordagens, amostra e resultados. E, conforme já discorrido, os estudos não são consensuais quanto à natureza dos impactos da política fiscal no crescimento econômico.

Diante dessa diversidade, a Tabela 1 - adaptada de Fernandes (2016) apresenta resumidamente, em ordem cronológica, pesquisas empíricas internacionais sobre a produtividade do gasto público, destacando a amostra selecionada, o período de análise, a técnica utilizada e os principais resultados encontrados.

\section{Tabela 1}

Pesquisas internacionais

\begin{tabular}{|c|c|c|c|c|}
\hline Autores & Amostra & Período & Técnica & Principais Resultados \\
\hline $\begin{array}{l}\text { Aschaver } \\
\text { (1989) }\end{array}$ & Estados Unidos & $\begin{array}{l}1949- \\
1985\end{array}$ & OLS & $\begin{array}{l}\text { Gastos públicos em infraestrutura } \\
\text { de ruas, rodovias, aeroportos, } \\
\text { transporte de massa, esgotos, } \\
\text { sistemas de água, etc. tiveram } \\
\text { poder explicativo para a } \\
\text { produtividade. }\end{array}$ \\
\hline Barro (1991) & Países & $\begin{array}{l}1960- \\
1985\end{array}$ & OLS & $\begin{array}{l}\text { O gasto de consumo do governo } \\
\text { foi negativamente relacionado } \\
\text { com o crescimento econômico, } \\
\text { reduzindo, portanto, } \\
\text { produtividade do capital privado. }\end{array}$ \\
\hline $\begin{array}{l}\text { Devarajan } \\
\text { et al. (1996) }\end{array}$ & $\begin{array}{l}43 \text { países em } \\
\text { desenvolvimento }\end{array}$ & $\begin{array}{l}1970- \\
1990\end{array}$ & $\begin{array}{c}\text { OLS / } \\
\text { Efeitos } \\
\text { fixos }\end{array}$ & $\begin{array}{l}\text { Aumento em } \\
\text { teve efeito postos correntes } \\
\text { crescimento econômico, } \\
\text { enquanto aumento em gastos de } \\
\text { capital teve efeito negativo. } \\
\text { Ademais, gastos aparentemente } \\
\text { produtivos, quando usados em } \\
\text { excesso, podem se tornar } \\
\text { improdutivos. }\end{array}$ \\
\hline
\end{tabular}




\begin{tabular}{|c|c|c|c|c|}
\hline Autores & Amostra & Período & Técnica & Principais Resultados \\
\hline $\begin{array}{l}\text { Kneller, } \\
\text { Bleaney e } \\
\text { Gemmell } \\
\text { (1999) }\end{array}$ & $\begin{array}{l}\text { Países } \\
\text { desenvolvidos }\end{array}$ & $\begin{array}{l}1970- \\
1995\end{array}$ & OLS & $\begin{array}{l}\text { A hipótese de que as variáveis } \\
\text { tiveram um impacto zero no } \\
\text { crescimento não foi rejeitada. } \\
\text { Além disso, aumento das } \\
\text { despesas produtivas aumentou } \\
\text { significativamente o crescimento. }\end{array}$ \\
\hline $\begin{array}{l}\text { Bleaney, } \\
\text { Gemmell \& } \\
\text { Kneller } \\
(2001)\end{array}$ & Países OCDE & $\begin{array}{l}1970- \\
1995\end{array}$ & LSDV & $\begin{array}{l}\text { Os gastos produtivos tinham } \\
\text { relação positiva com } \\
\text { crescimento econômico. }\end{array}$ \\
\hline $\begin{array}{l}\text { Arraes \& } \\
\text { Teles (2001) }\end{array}$ & $\begin{array}{l}\text { Regiōes } \\
\text { Brasileiras }\end{array}$ & $\begin{array}{l}1981- \\
1995\end{array}$ & $\begin{array}{l}\text { Efeitos } \\
\text { fixos }\end{array}$ & $\begin{array}{l}\text { Gastos em educação e cultura e, } \\
\text { em seguida, em saúde e } \\
\text { saneamento e em transportes, } \\
\text { foram os mais positivos sobre o } \\
\text { crescimento econômico. }\end{array}$ \\
\hline $\begin{array}{l}\text { Herrera \& } \\
\text { Blanco } \\
\text { (2004) }\end{array}$ & Brasil & $\begin{array}{l}1950- \\
2000\end{array}$ & ARDL & $\begin{array}{l}\text { No longo prazo a elasticidade- } \\
\text { renda do estoque de capital } \\
\text { público foi maior que a do setor } \\
\text { privado }\end{array}$ \\
\hline $\begin{array}{l}\text { Rocha \& } \\
\text { Giuberti } \\
\text { (2007) }\end{array}$ & $\begin{array}{l}\text { Estados } \\
\text { brasileiros }\end{array}$ & $\begin{array}{l}1986- \\
2003\end{array}$ & LSDV & $\begin{array}{l}\text { Todos os gastos produtivos - } \\
\text { capital, educação, transporte e } \\
\text { comunicação - tiveram um efeito } \\
\text { positivo e estatisticamente } \\
\text { significante sobre o crescimento, } \\
\text { com exceção da saúde. }\end{array}$ \\
\hline $\begin{array}{l}\text { Bose, Haque } \\
\text { \& Osborn } \\
\text { (2007) }\end{array}$ & $\begin{array}{l}30 \text { países em } \\
\text { desenvolvimento }\end{array}$ & $\begin{array}{l}1970- \\
1990\end{array}$ & SUR & 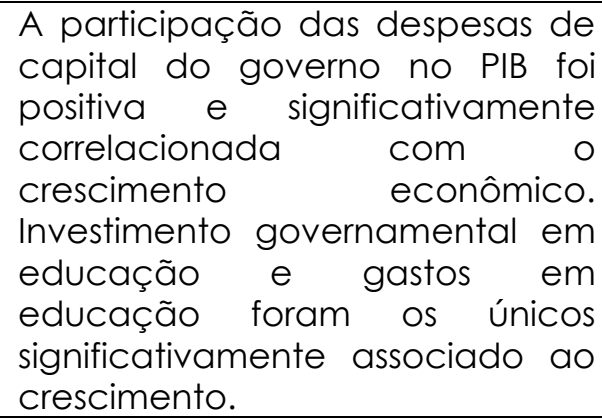 \\
\hline $\begin{array}{l}\text { Ghosh \& } \\
\text { Gregoriou } \\
\text { (2008) }\end{array}$ & $\begin{array}{l}\text { Países em } \\
\text { desenvolvimento }\end{array}$ & $\begin{array}{l}1972- \\
1999\end{array}$ & GMM & $\begin{array}{l}\text { Gasto de capital negativamente } \\
\text { associado com o crescimento } \\
\text { econômico, diferentemente do } \\
\text { gasto corrente, corroborando } \\
\text { com Devarajan, Swaroop e Zou } \\
\text { (1996). }\end{array}$ \\
\hline $\begin{array}{l}\text { Moreno- } \\
\text { Dodson } \\
\text { (2008) }\end{array}$ & $\begin{array}{l}\text { Países em } \\
\text { desenvolvimento }\end{array}$ & $\begin{array}{l}1970- \\
2006\end{array}$ & $\begin{array}{l}\text { OLS, SUR } \\
\text { e GMM }\end{array}$ & $\begin{array}{l}\text { Gastos produtivos (despesas com } \\
\text { educação e saúde e alguns } \\
\text { gastos econômicos, como } \\
\text { transporte e comunicações) } \\
\text { foram a categoria de gastos mais } \\
\text { relevantes para o crescimento. }\end{array}$ \\
\hline $\begin{array}{l}\text { Cavallo \& } \\
\text { Daude } \\
\text { (2008) }\end{array}$ & $\begin{array}{l}116 \text { países em } \\
\text { desenvolvimento }\end{array}$ & $\begin{array}{l}1980- \\
2006\end{array}$ & GMM & $\begin{array}{l}\text { Evidências de efeito crowding-out } \\
\text { robusto, o investimento público } \\
\text { isoladamente foi era suficiente } \\
\text { para impactar positivamente no } \\
\text { investimento privado. Gastos em } \\
\text { obras públicas poderiam } \\
\text { facilmente ser ineficientes ou ter } \\
\text { efeitos adversos no setor privado. }\end{array}$ \\
\hline
\end{tabular}




\begin{tabular}{|c|c|c|c|c|}
\hline Autores & Amostra & Período & Técnica & Principais Resultados \\
\hline $\begin{array}{l}\text { Rodrigues \& } \\
\text { Teixeira } \\
\text { (2010) }\end{array}$ & $\begin{array}{l}\text { União, estados e } \\
\text { municípios }\end{array}$ & $\begin{array}{l}1948- \\
1998\end{array}$ & OLS & $\begin{array}{l}\text { Os gastos em investimentos } \\
\text { tiveram maior efeito positivo para } \\
\text { o crescimento, ao contrário dos } \\
\text { gastos com consumo, subsídios e } \\
\text { transferências. A esfera estadual } \\
\text { apresentou maior capacidade de }\end{array}$ \\
\hline & & & & $\begin{array}{l}\text { impulsionar } \\
\text { econômico. }\end{array}$ \\
\hline $\begin{array}{l}\text { Souza et al. } \\
(2010)\end{array}$ & $\begin{array}{l}\text { Brasil (dados } \\
\text { consolidados) }\end{array}$ & $\begin{array}{l}1980- \\
2008\end{array}$ & ARDL & $\begin{array}{l}\text { Aumentos dos gastos públicos } \\
\text { produtivos (funções habitação, } \\
\text { urbanismo, indústria, comércio, } \\
\text { serviços, comunicação, etc) } \\
\text { relacionados ao crescimento do } \\
\text { produto no longo prazo. }\end{array}$ \\
\hline $\begin{array}{l}\text { Baynaktar \& } \\
\text { Moreno- } \\
\text { Dodson } \\
\text { (2010) e } \\
\text { Moreno- } \\
\text { Dodson \& } \\
\text { Baynaktar } \\
\text { (2011) }\end{array}$ & $\begin{array}{l}\text { Países em } \\
\text { desenvolvimento }\end{array}$ & $\begin{array}{l}1970- \\
2005\end{array}$ & $\begin{array}{l}\text { OLS, SUR } \\
\text { e GMM }\end{array}$ & $\begin{array}{l}\text { Os gastos públicos podem ser um } \\
\text { fator determinante no } \\
\text { crescimento através de seus } \\
\text { componentes produtivos e } \\
\text { "centrais", que também podem } \\
\text { impactar a função de produção } \\
\text { do setor privado. }\end{array}$ \\
\hline
\end{tabular}

Os gastos em saúde, saneamento, educação, cultura, investimento,

Bogoni, Hein \& Beuren (2011)
Maiores cidades da Região Sul
2000 2004 habitação assistência e previdência social tiveram relação positiva com o crescimento. Assim, os gastos públicos podem impulsionar o desenvolvimento econômico.

Nos países em desenvolvimento, municípios com renda per capita abaixo da linha de pobreza

Divino \& Silva Jr. (2012)
Municípios

brasileiros
$1991-$ 2000
OLS conseguiriam aumentar 0 crescimento econômico ao gastarem mais em despesas correntes do que municípios que estão acima da linha.

O aumento dos gastos públicos em infraestrutura como proporção do PIB impactaria de forma positiva e significativa $\bigcirc$ crescimento econômico dos estados brasileiros. Os gastos públicos não contribuíram para o crescimento
econômico, provavelmente por

Ogundipe \& Oluwatobi Nigéria (2013)

$1970-$ 2009 integração questões ligadas à corrupção, a projetos sem utilidade e sem continuidade.

Os gastos públicos com saúde e com infraestrutura melhoraram a produtividade de determinadas

Kneller \& Misch (2014) África do Sul $\quad 2002-$
2006
OLS empresas. Ademais, mudanças na composição das despesas públicas são capazes de afetar positivamente a produtividade de determinadas empresas. 


\begin{tabular}{|c|c|c|c|c|}
\hline Autores & Amostra & Período & Técnica & Principais Resultados \\
\hline $\begin{array}{l}\text { Fournier \& } \\
\text { Johansson } \\
\text { (2016) }\end{array}$ & Países da OCDE & $\begin{array}{l}2009- \\
2013\end{array}$ & OLS & $\begin{array}{l}\text { O aumento da participação do } \\
\text { investimento público no gasto } \\
\text { total do governo gerou grandes } \\
\text { ganhos de crescimento. }\end{array}$ \\
\hline \multirow{2}{*}{$\begin{array}{l}\text { Degenhart } \\
\text { et al. }(2016)\end{array}$} & \multirow{2}{*}{$\begin{array}{l}\text { Maiores } \\
\text { municípios da } \\
\text { região Norte }\end{array}$} & \multirow[t]{2}{*}{2010} & \multirow{2}{*}{$\begin{array}{l}\text { Modelo } \\
\text { não linear } \\
\text { multivariá } \\
\text { vel }\end{array}$} & $\begin{array}{l}\text { Os resultados } \\
\text { relação enidenciaram } \\
\text { econômico e os gastos públicos }\end{array}$ \\
\hline & & & & $\begin{array}{l}\text { com Assistência, Saúde e } \\
\text { Educação. }\end{array}$ \\
\hline $\begin{array}{l}\text { Sousa \& } \\
\text { Paulo (2016) }\end{array}$ & Estados & $\begin{array}{l}1995- \\
2010\end{array}$ & $\begin{array}{l}\text { Efeitos } \\
\text { fixos }\end{array}$ & $\begin{array}{l}\text { Os gastos agregados dos Estados } \\
\text { brasileiros apresentaram-se } \\
\text { positivamente relacionados ao } \\
\text { crescimentoranto econômico. } \\
\text { Ademais, o gasto com saúde foi } \\
\text { improdutivo no nível agregado. }\end{array}$ \\
\hline $\begin{array}{l}\text { Makuyana } \\
\text { \& } \\
\text { Odhiambo }\end{array}$ & Zimbábue & $\begin{array}{l}1970- \\
2014\end{array}$ & ARDL & $\begin{array}{l}\text { Gastos públicos com investimento } \\
\text { tiveram impacto no crescimento } \\
\text { econômico a curto prazo. }\end{array}$ \\
\hline
\end{tabular}

(2017) Ntembe,

Amin \&

Tawah.

1977

(2017)

$2015 \quad$ ARDL

Gastos públicos com investimento tiveram impacto no crescimento econômico, no curto e longo prazo.

Gastos em educação, saúde,

Piccoli,

$\begin{array}{llll}\text { Baronchello } & \text { Municípios do } & 2013- & \\ \text { \& Nardi } & \text { Alto Vale do Rio } & 2015 & \text { OLS } \\ \text { do Peixe } & 2017) & & \end{array}$
assistência, cultura, urbanismo, agricultura e segurança foram (2017) do Peixe considerados produtivos e capazes de gerar externalidades positivas.

Os gastos em administração e planejamento, judiciário,

Neduziak \& Correia (2017)

Estados

1995

2011

OLS e

Efeitos

fixos habitação e urbanismo e assistência e previdência foram produtivos; e os gastos em educação e cultura e legislativo, improdutivos.

\begin{tabular}{|c|c|c|c|c|}
\hline $\begin{array}{l}\text { Campo \& } \\
\text { Mendoza } \\
\text { (2018) }\end{array}$ & $\begin{array}{l}\text { Departamentos } \\
\text { da Colômbia } \\
\text { (estados) }\end{array}$ & $\begin{array}{l}1984- \\
2012\end{array}$ & OLS & $\begin{array}{l}\text { Gastos com operação e } \\
\text { investimento tiveram efeito } \\
\text { positivo e significativo no PIB da } \\
\text { Colômbia. }\end{array}$ \\
\hline Lupu (2018) & $\begin{array}{l}\text { Países da Europa } \\
\text { Central e } \\
\text { Oriental }\end{array}$ & $\begin{array}{l}1995- \\
2015\end{array}$ & ARDL & $\begin{array}{l}\text { Gastos com educação e saúde } \\
\text { tiveram impacto positivo na } \\
\text { economia, enquanto gastos com } \\
\text { defesa, assuntos econômicos, } \\
\text { serviços públicos e assistência } \\
\text { social tiveram impacto negativo. }\end{array}$ \\
\hline $\begin{array}{l}\text { Yilmaz } \\
(2018)\end{array}$ & $\begin{array}{l}\text { Províncias da } \\
\text { Turquia }\end{array}$ & $\begin{array}{l}1975- \\
2001\end{array}$ & OLS & $\begin{array}{l}\text { Gastos com investimento tiveram } \\
\text { um impacto positivo na } \\
\text { economia. Observou-se que o } \\
\text { governo investiu excessivamente } \\
\text { em transporte e serviços, } \\
\text { educação, saúde e segurança. }\end{array}$ \\
\hline
\end{tabular}

Legenda: OLS - Ordinary Least Square (Mínimos Quadrados Ordinários); LSDV - Least Square Dummy Variable (Mínimos Quadrados com Variável Dummy); SUR - Seemingly Unrelated Regression (Regressões aparentemente não relacionadas); GMM - Generalized Method of Moments (Método de Momentos Generalizados); ARDL - autoregressive-distributed lag mode/ (modelo autorregressivo de defasagens distribuídas). 
Do ponto de vista empírico, os estudos que estimaram o impacto de gastos públicos no crescimento econômico geralmente fornecem evidências de que a composição dos gastos é um fator importante para o crescimento (Devarajan et al., 1996; Rocha \& Giuberti, 2007; Carboni \& Medda, 2011; Kneller \& Misch, 2014; Sousa \& Paulo, 2016; Neduziak \& Correia, 2017; Lupu, 2018; Yilmaz, 2018).

Nesses estudos, os resultados demonstram que a estruturação do gasto público causa diferentes efeitos sobre o crescimento econômico. Por exemplo, investimentos em infraestrutura normalmente aumentam o estoque de capital físico que, por sua vez, impacta no crescimento de longo prazo (Johansson, 2016). Assim, gastos em transporte, comunicação e defesa se associam positivamente ao crescimento econômico. Entretanto, Bose, Haque e Osborn (2007) observaram que isso não ocorreu, pois a a amostra estudada demonstrou evidência antagônica.

Considerando as diversas estruturações dos gastos públicos, as constantes restrições orçamentárias e os recorrentes ajustes fiscais, observa-se que $A$ identificação do nível de contribuição que cada um dos componentes do gasto têm sobre o crescimento é uma informação relevante à tomada de decisão, que permite otimização da alocação, sem que implique necessariamente em aumento do gasto público total (Giuberti \& Rocha, 2015; Neduziak \& Correia, 2017).

A abordagem usualmente empregada, como demonstrado no modelo de crescimento endógeno de Barro (1990), é a de gastos produtivos e improdutivos. Sob a ótica empírica, os gastos produtivos afetam positivamente o crescimento econômico, enquanto os gastos improdutivos não. Portanto, um gasto do governo é nulo se não afetar a produtividade do setor privado; caso rivalize com o gasto do setor privado, é considerado improdutivo; e, caso afete positivamente o crescimento econômico de longo prazo, é considerado um gasto produtivo (Aschaver, 1989; Barro, 1990; Devarajan et al., 1996; Rocha \& Giuberti, 2007; Carboni \& Medda, 2011; Kneller \& Misch, 2014; Sousa \& Paulo, 2016; Neduziak \& Correia, 2017; Lupu, 2018; Yilmaz, 2018).

Segundo Devarajan et al. (1996), a classificação do gasto público como produtivo ou improdutivo deve decorrer das informações reveladas pelos resultados a partir de uma análise econométrica. Para os autores, não se deve definir, a princípio, quais componentes do gasto público são produtivos ou não. Assim, são os resultados econométricos que demonstram a classificação dos gastos públicos.

Ademais, segundo esses autores, gastos produtivos podem se tornar improdutivos se realizados em excesso. Fato também observado nos resultados encontrados por Miller e Russek (1997), que demonstraram que aumentos nos gastos com defesa, saúde e seguridade social, gastos normalmente produtivos, reduziam o crescimento econômico em países em desenvolvimento, visto que representavam uma parcela expressiva do orçamento desses países.

Dessa forma, extrai-se da literatura a existência de um limite ótimo para a participação de cada gasto do orçamento na promoção do crescimento econômico. Além disso, as evidências empíricas encontradas indicam que é possível, por meio da realocação de gastos públicos, promover crescimento econômico, mesmo quando há a impossibilidade de aumentar o nível de gastos públicos durante vários anos (Devarajan et al., 1996; Rocha \& Giuberti, 2007; 
Carboni \& Medda, 2011; Sousa \& Paulo, 2016; Neduziak \& Correia, 2017; Lupu, 2018; Yilmaz, 2018).

No Brasil, o arranjo federativo pactuado em 1988 apresenta um caráter descentralizador, tendo em vista a autonomia política e fiscal dos estados e municípios, com atribuições e funções constitucionais, destacando-se a intensificação do volume de recursos repassados aos governos regionais e locais via transferências intergovernamentais (Rezende, 2010).

Consequentemente, houve um impacto no alcance de uma política fiscal idealizada pelo Governo Federal, tendo em vista a incompatibilidade entre políticas de estabilização macroeconômica e políticas de provisão de bens e serviços, que são, em grande parte, providos pelos governos subnacionais. Assim, há uma condição peculiar dos diferentes estágios de desenvolvimento das unidades federadas na busca pela definição de políticas fiscais que possam contribuir para o crescimento econômico do país (Macedo \& Corbari, 2009; Sousa \& Paulo, 2016).

O contexto econômico brasileiro atual de resultados fiscais insatisfatórios e de trajetória ascendente da dívida pública, discorrido anteriormente, também é refletido nos entes subnacionais. Nos municípios, segundo Cardoso, Pansani, Serrano e Wilbert (2018), há uma deterioração das finanças públicas, cujo diagnóstico é comumente explicado pela redução das receitas públicas concomitantemente à manutenção ou ao aumento das despesas. Segundo os autores, essa condição, se não revertida ou controlada, resultará em insustentabilidade da situação fiscal no longo prazo, nos entes municipais.

Considerando essa deterioração das finanças públicas municipais, as peculiaridades do arranjo federativo brasileiro e a necessidade de estabilização macroeconômica nacional, é importante identificar o nível de contribuição que cada um dos componentes do gasto público municipal tem sobre o crescimento econômico, tendo em vista a relevância dessa informação à tomada de decisão.

\section{PROCEDIMENTOS METODOLÓGICOS}

\subsection{Modelo Teórico}

Para atingir o objetivo de analisar a influência da composição dos gastos públicos municipais na promoção do crescimento econômico, utilizou-se o modelo analítico de Devarajan et al. (1996). O modelo permite evidenciar a diferença entre os gastos produtivos e improdutivos, bem como a maneira pela qual uma realocação desses gastos pode afetar a taxa de crescimento econômico de longo prazo. Os citados autores realizaram estudo com 43 países em desenvolvimento durante 20 anos demonstrando evidências de que aumento na divisão de despesas correntes tem efeito positivo e estatisticamente significante no crescimento.

Portanto, assume-se uma função de produção com três argumentos: o estoque privado de capital (k), e dois tipos de gastos públicos, "gl" e "g2", (produtivo e o improdutivo, respectivamente). Se a função de produção é do tipo Constant Elasticity of Substitution (CES), que se refere a uma medida para determinar o grau de facilidade ou dificuldade com que os produtores substituem 
um fator de produção para outro diante do emprego dos mais diversos fatores de produção (Sousa \& Paulo, 2016), então:

$$
y=f\left(k, g_{1}, g_{2}\right)=\left[\alpha k^{-\zeta}+\beta g_{1}^{-\zeta}+\gamma g_{2}^{-\zeta}\right]^{\frac{1}{\zeta}}
$$

Onde: $\alpha>0, \beta \geq 0, \gamma \geq 0, \alpha+\beta+\gamma=1, \zeta$ (parâmetro da função CES) $\geq-1$

Conforme Barro (1990), assume-se que os gastos públicos são financiados de acordo com a seguinte relação:

$$
\tau y=g_{1}+g_{2}
$$

Onde $\tau y$ é uma alíquota de imposto fixa sobre a renda. $g_{1}$ é dada por:

Deste modo, a parcela dos gastos totais, $\phi(0 \leq \phi \leq 1)$, que é alocada para

$$
g_{1}=\phi \tau y \quad g_{2}=(1-\phi) \tau y
$$

O agente representativo, de acordo com o consumo (c) e o capital (k), tomará as decisões do governo de forma a maximizar o seu bem-estar:

$$
U=\int_{0}^{\infty} u(c) e^{-\rho t} d t
$$

Onde $\rho$ é a taxa de preferência temporal.

Sujeito a:

$$
\dot{k}=(1-\tau) y-c
$$

Especializa-se a função de utilidade para a forma isoelástica, com a finalidade de gerar soluções analíticas:

$$
u(c)=\frac{c^{1-\sigma}-1}{1-\sigma}
$$

Ao substituir (6) em (4) e maximizando sujeito a (1), (2), (3) e (5), tem-se a seguinte equação de crescimento do consumo:

$$
\frac{\dot{c}}{c}=\frac{\alpha(1-\tau)\left\{\alpha+(g / k)^{-\zeta}\left[\beta \phi^{\zeta}+\gamma(1-\phi)^{-\zeta}\right]\right\}^{-(1+\zeta) / \zeta}-\rho}{\sigma}
$$

Considerando que, ao longo do estado estacionário, $\tau$ é constante, $\frac{g}{y}$ será dada pela seguinte equação:

$$
\frac{g}{k}=\left\{\left[\tau^{\zeta}-\beta \phi^{-\zeta}-\gamma(1-\phi)^{-\zeta}\right] / \alpha\right\}^{1 / \zeta}
$$


Ao substituir (8) em (7), tem-se a taxa de crescimento do consumo $(\lambda)$ :

$$
\lambda=\frac{\alpha(1-\tau)\left\{\frac{\alpha \tau}{\left[\tau^{\zeta}-\beta \phi^{\zeta}-\gamma(1-\phi)^{-\zeta}\right.}\right]^{\frac{1+\zeta}{\zeta}}+\rho}{\sigma}
$$

Ao derivar uma relação entre taxa de crescimento do consumo $(\lambda)$ e a parcela de gastos governamentais destinados a $g_{1}(\phi)$, da equação (9), obtemse:

$$
\frac{d \lambda}{d \phi}=\frac{\alpha(1-\tau)(1+\zeta)\left[\alpha \tau^{\zeta}\right]^{-(1+\zeta) / \zeta}\left[\beta \phi^{(1+\zeta)}-\gamma(1-\phi)^{-1(1+\zeta)}\right]}{\sigma\left[\tau^{\zeta}-\beta \phi^{-\zeta}-\gamma(1-\phi)^{-\zeta}\right]^{-1 / \zeta}}
$$

Deste modo, pode-se inferir que gasto produtivo é aquele que aumenta a taxa de crescimento do estado estacionário. Portanto, da expressão (10), podese observar $g_{1}$ como produtivo quando $\frac{d \lambda}{d \phi}>0$. Ao assumir que $\lambda>0$, então a expressão (10) será positiva se:

$$
(1+\zeta)\left[\beta \phi^{(1+\zeta)}-\gamma(1-\phi)^{-(1+\zeta)}\right]>0
$$

Nesta expressão (1 1), $\zeta \geq-1$, implicando em $\frac{d \lambda}{d \phi}>0$, se:

$$
\frac{\phi}{1-\phi}<\left(\frac{\beta}{\gamma}\right)^{\theta}
$$

Onde: $\theta=1 /(1+\zeta)$, medindo a elasticidade de substituição. Ao observar a condição (12), tem-se que o valor de $\theta$ depende da produtividade dos gastos $\left(\beta\right.$ e $\gamma$ ) e da composição inicial dos gastos ( $\phi$ para $g_{1}$ e $1-\phi$ para $\left.g_{2}\right)$. Deste modo, uma recomposição de gastos não influenciará o crescimento do PIB se o valor inicial de $\theta$ for elevado.

Portanto, a escolha de $\phi$ pode aumentar o crescimento segundo a seguinte expressão:

$$
\frac{\phi^{*}}{1-\phi^{*}}<\left(\frac{\beta}{\gamma}\right)^{\theta} \Rightarrow \frac{\beta^{\theta}}{\phi^{*}}=\frac{\gamma^{\theta}}{1-\phi^{*}}
$$

Onde: $\phi^{*}$ é a escolha ótima de composição dos gastos, visto que tanto $\theta$, quanto $\beta$ e $\gamma$ são constantes, assim, a variável de escolha para o governo é $\phi$, existindo um $\phi^{*}$ correspondente a maior produtividade possível do gasto por unidade despedida. 
Empiricamente, para operacionalizar o modelo analítico proposto por Devarajan et al. (1996) com a finalidade de avaliar a relação existente entre os componentes do gasto público dos municípios brasileiros no período de 2001 a 2016, define-se inicialmente o seguinte modelo linear:

$$
Y_{i(t+1 ; t+5)}=\alpha_{i}+\delta_{t}+\beta^{\prime} X_{i t}+\mu_{i}
$$

Onde: $\Upsilon_{i(t+1 ; t+5)}$ é a taxa média de crescimento econômico anual (PIB per capita) do município $i$, no período de cinco anos (de modo a reduzir a possibilidade de endogeneidade); $\alpha_{i}$ é o intercepto específico de cada município; $\delta_{t}$ é a tendência determinística temporal que mostra a evolução compartilhada pelas economias; $\beta^{\prime}$ é o coeficiente das variáveis independentes; $X_{i t}$ é um vetor que representa todas as variáveis independentes (gastos públicos); e $\mu_{i}$ é o termo de erro aleatório.

As variáveis independentes $\left(X_{i t}\right)$ foram divididas em dois tipos: razão entre o gasto total e o PIB para cada município e período $\left(G T_{i t} / P I B_{i t}\right)$ e vetor que representa a razão entre o gasto público por função e o gasto total para cada munícipio e período $\left(G_{i t} / G T_{i t}\right)$.

A inclusão da razão $G T_{i t} / P I B_{i t}$ permite controlar os efeitos de nível e financiamento do gasto sobre a taxa de crescimento (Devarajan et al., 1996; Rocha \& Giuberti, 2007; Neduziak \& Correia, 2017).

O trabalho de Rocha e Giuberti (2007) sugere que as razões do gasto e o crescimento devem ter uma relação não-linear. Segundo o modelo teórico de Devarajan et al. (1996), em países em desenvolvimento, quando as parcelas de gastos produtivos são grandes, a relação do gasto com o crescimento pode se tornar negativa, pois, à medida que a parcela aumenta, observam-se retornos decrescentes de escala e, eventualmente, a relação entre as duas variáveis se torna negativa.

Considerando essa relação teórica não-linear e a análise das características de desenvolvimento dos municípios brasileiros, utiliza-se a seguinte especificação quadrática adicional, similarmente aos procedimentos adotados por Rocha e Giuberti (2007), Divino e Silva Júnior (2012) e Sousa e Paulo (2016):

$$
Y_{i(t+1 ; t+5)}=\alpha_{i}+\delta_{t}+\beta^{\prime} X_{i t}+\beta^{\prime \prime} X_{i t}^{2}+\mu_{i}
$$

Onde: $X_{i t}^{2}$ é um vetor que representa todas as variáveis independentes (gastos públicos) ao quadrado. Conforme Devajaran, Swarrop e Zou (1996), caso a regressão quadrática se mostre significativa, a apuração da razão ótima de gasto público é verificada pelo efeito máximo da variável $X$ em um determinado ponto. Derivando $Y$ em relação a $X$, temos:

$$
X^{*}=-\frac{\beta^{\prime}}{2 \beta^{\prime \prime}}
$$


Onde: $X^{*}$ é o nível ótimo de gastos capaz de maximizar parcialmente o crescimento da renda per capita $Y_{i}$. A função quadrática foi inicialmente utilizada porque os autores que pesquisaram o assunto a utilizaram. Outra razão é o impacto dos gastos no crescimento nem sempre ser linear, porque as curvas de crescimento são naturalmente exponenciais. Portanto, testou-se essa forma das variáveis de gasto e verificou-se que em alguns casos a função quadrática é estatisticamente significante, enquanto a relação linear não.

\subsection{Dados e Variáveis Utilizados}

Para alcançar o objetivo proposto, constituiu-se a amostra com 5.533 municípios: 5.044 classificados como não desenvolvidos e 489 classificados como desenvolvidos. Diferentemente de Devarajan et al. (1996), que analisou países, os dados do presente estudo se referem a municípios, os quais são unidades constante da federação brasileira. Essa granularidade menor de unidades analisadas contribui para melhor compreensão do país que o compõe que é o Brasil, afinal, o total de todos esses municípios resultam na composição única da federação.

A classificação dos municípios em desenvolvidos e não desenvolvidos foi obtida por meio do Índice Firjan de Desenvolvimento Municipal (IFDM 2018 - ano base 2016). Consideram-se desenvolvidos os municípios com índice superior (ou igual) a 0,8 ponto, de acordo com a classificação do próprio Instituto Firjan. Como o índice é de 0 a 1, o Firjan estabeleu na metodologia quatro extratos de desenvolvimento de acordo com a nota do IFDM: alto desenvolvimento 10,8 a $1,0)$, desenvolvimento moderado $(0,6$ a 0,8$)$, desenvolvimento regular $(0,4$ a 0,6$)$ e baixo desenvolvimento $(0,0$ a 0,4). A decomposição dessa forma, pegando os municípios muito desenvolvidos, objetivou testar se o modelo se aplicava, mesmo a maior parte da amostra sendo de municípios não desenvolvidos.

Em relação ao crescimento econômico, o conceito adotado é o da média de crescimento dos cinco anos subsequentes, calculada pelos PIB's municipais per capita fornecidos pelo Instituto Brasileiro de Geografia e Estatística (IBGE). Os dados concernentes aos gastos públicos municipais (registros contábeis da execução orçamentária por categoria funcional) estão disponibilizados nos bancos de dados do Tesouro Nacional (TN): Finanças do Brasil (Finbra) e Sistema de Informações Contábeis e Fiscais do Setor Público Brasileiro (Siconfi).

A classificação por categoria econômica (corrente e de capital) é muito ampla no contexto do setor público, em que se observa se há formação de um bem de capital (despesa de capital) ou não (despesa corrente). Por ser muito ampla, preferiu-se a classificação funcional, que tem uma granularidade maior e é mais detalhada que a classificação por categoria econômica.

Assim, a variável gasto público por função, representada nas especificações econométricas como $X_{i t}$ (vetor que representa todas as variáveis independentes) e detalhada pelo vetor que representa a razão entre o gasto público por função e o gasto total $\left(G_{i t} / G T_{i t}\right)$, é descrita, para cada município e período, da seguinte forma:

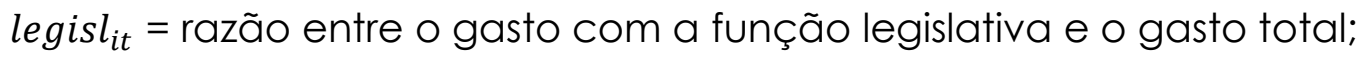

$j u d_{i t}=$ razão entre o gasto com a função judiciária e o gasto total; 
$a d m \_$lan $_{i t}=$ razão entre $\mathrm{O}$ gasto com a função administração e planejamento e o gasto total;

$\operatorname{agric}_{i t}=$ razão entre o gasto com a função agricultura e o gasto total;

$\operatorname{com}_{i t}=$ razão entre o gasto com a função comunicações e o gasto total; total;

seg_pub $b_{i t}=$ razão entre o gasto com a função segurança pública e o gasto

$e d u c_{\_} c u l t_{i t}=$ razão entre o gasto com a função educação e cultura e o gasto total;

energ $_{i t}=$ razão entre o gasto com a função energia e recursos minerais e o gasto total;

$h a b_{\_} u r b_{i t}=$ razão entre o gasto com a função habitação e urbanismo e o gasto total;

ind_com_serv $v_{i t}=$ razão entre o gasto com a função indústria, comércio e serviços e o gasto total;

sau_san ${ }_{i t}=$ razão entre o gasto com a função saúde e saneamento e o gasto total;

ass_prev $v_{i t}=$ razão entre o gasto com a função assistência e previdência e o gasto total; e

trans $_{i t}=$ razão entre o gasto com a função transporte e o gasto total.

Os resultados do teste para o risco de colinearidade das variáveis independentes demonstraram que o fator de inflação da variância (VIF) foi menor do que 10, não existindo evidências de multicolinearidade, o que também pode ser verificado na matriz de correlação das variáveis.

Com o objetivo de verificar a adequabilidade do modelo, foram realizados testes de especificação. Para verificar a aderência do modelo de efeitos fixos, foi realizado o teste $\mathrm{F}$ (teste de Chow). A estatística do teste $\mathrm{F}$, bem como seu respectivo $\mathrm{p}$-valor indicou que o modelo de efeitos fixos era melhor que o pool.

Na sequência, utilizou-se o teste de Hausman para verificar a consistência dos efeitos aleatórios. Uma vez que o teste apresentou significância estatística, o modelo ideal verificado foi o modelo de efeitos fixos. Assim, não foi necessária a realização do teste $L M$ de Breusch-Pagan. Para minimizar o nível de endogeneidade, utilizou-se, na variável dependente, a média de crescimento econômico no período de cinco anos, conforme em Devarajan et al. (1996), Ghosh e Gregoriou (2008), Rocha e Giuberti (2007) e Sousa e Paulo (2016).

Nos testes de Wald e de Breusch-Pagan, para verificar a existência de heterocedasticidade, a hipótese nula de homocedasticidade dos resíduos foi rejeitada. Da mesma forma, a hipótese nula de autocorrelação de primeira ordem nos resíduos do teste de Wooldridge foi rejeitada. Portanto, todos os modelos apresentados foram estimados com erros-padrão robustos em relação à heterocedasticidade e à correlação serial (erros-padrão de Rogers).

Para capturar o efeito das características não observáveis de cada município, utilizaram-se estimações pelo modelo de efeitos fixos. Tais estimações 
compreenderam os municípios brasileiros que apresentavam informações necessárias sobre os gastos públicos e PIB. Assim, foi utilizado painel não balanceado com efeitos fixos, analisando 5.533 municípios e perfazendo um total de 58.677 observações. Adotou-se como melhor modelo ajustado o modelo de efeito fixo com controle do tempo e sem a deflação dos gastos públicos e do PIB. Como variáveis de controle são difíceis de serem obtidas continuamente no nível de município em uma linha temporal extensa, foi utilizado somente variável dummy de ano.

Por fim, foi realizada análise por região (Norte, Nordeste, Centro-Oeste, Sudeste, Sul) para verificar a existência de diferenças significativas entre elas no modelo aplicado. Como algumas regiões são economicamente mais desenvolvidas, os resultados podem demonstrar se essas diferenças são representativas quanto à otimização do gasto público. Não foi realizada análise do cenário político durante o período analisado porque o Brasil é uma federação que possui 37 partidos políticos, o que dificulta essa análise nos 5.533 municípios (Tarouco e Madeira, 2013; Maciel, Alarcon e Gimenes, 2017).

\section{ANÁLISE E DISCUSSÃO DOS RESULTADOS}

A Tabela 2 apresenta as estatísticas descritivas das variáveis dependentes e independente para amostra e período de estudo. Observa-se que os municípios da amostra, no período de 2001 a 2016, tiveram taxa média de crescimento econômico per capita, no período de cinco anos, de $6,65 \%$. 
Tabela 2

Estatísticas descritivas - média das variáveis dependentes e independente (\% a. a.)

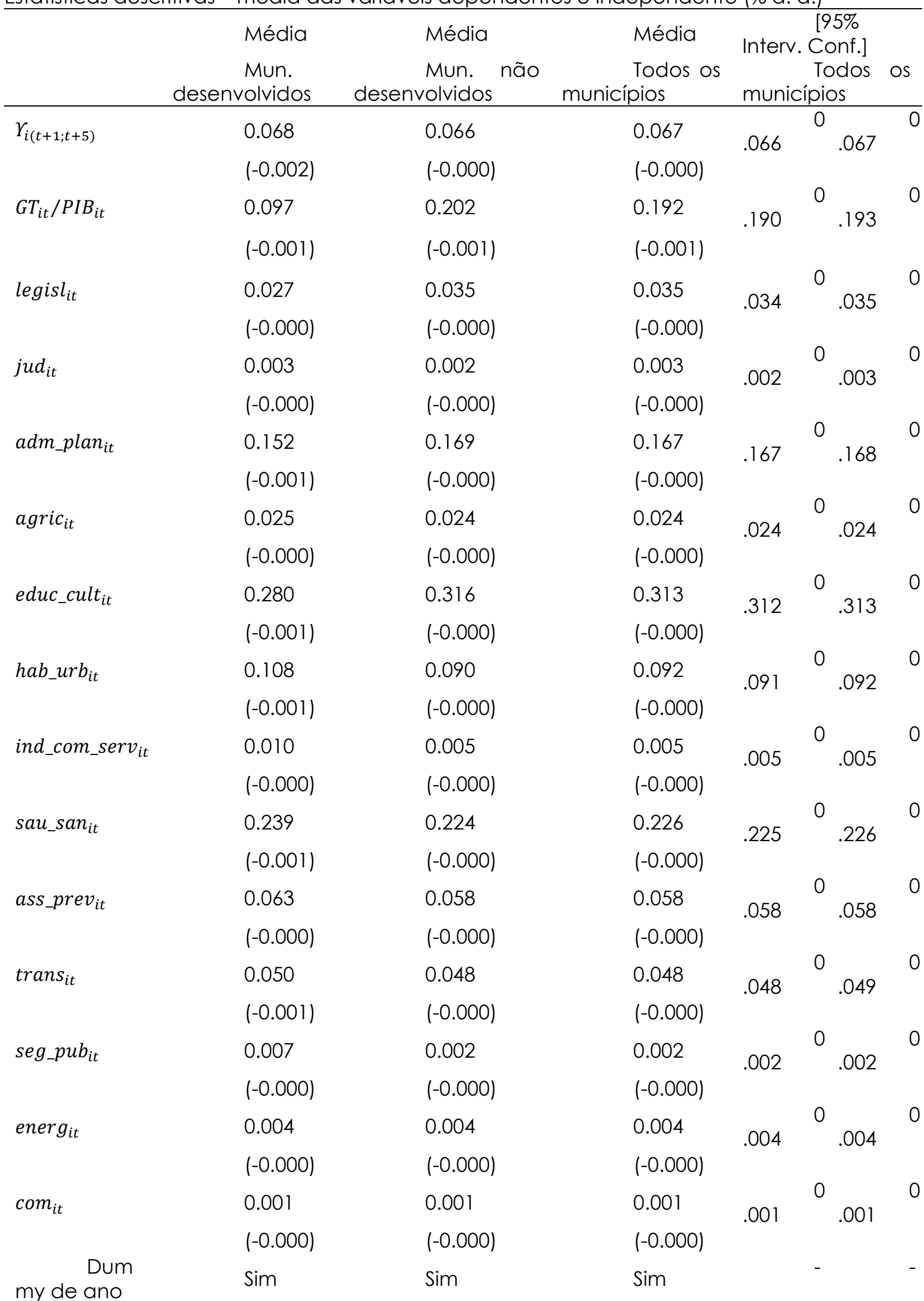

Fonte: Elaboração própria a partir dos dados do Tesouro Nacional e do IBGE. Erros padrões robustos entre parênteses. ${ }^{* * *} p<0.01,{ }^{* *} p<0.05,{ }^{*} p<0.1$ 
Observa-se certa similaridade entre os municípios desenvolvidos e os municípios não desenvolvidos analisados. Contudo, verifica-se que os gastos com saúde e saneamento, habitação e urbanismo, assistência e previdência, transporte, agricultura, indústria, comércio e serviço e segurança pública resultaram em parcelas maiores nos municípios desenvolvidos. Enquanto, os gastos com educação e cultura, administração e planejamento, legislativo e energia resultaram em parcelas maiores nos municípios não desenvolvidos.

No que se referem aos gastos por função mais representativos em relação ao gasto público total, os gastos com educação e cultura, saúde e saneamento, administração e planejamento, habitação e urbanismo e assistência e previdência compreenderam $84,23 \%$ nos municípios desenvolvidos e $85,72 \%$ nos não desenvolvidos.

Os gastos com educação e cultura e com saúde e saneamento, como esperado, representaram a maior proporção do gasto público municipal $(51,90 \%$ nos municípios desenvolvidos e 54,05\% nos não desenvolvidos). Essa predominância da saúde e educação sobre as demais classificações funcionais decorre da obrigação constitucional de aplicação de parte da receita de impostos com tais gastos.

\subsection{Estimações Lineares do Modelo Empírico}

Os resultados das estimações lineares do modelo empírico são apresentados na Tabela 3, apresentando os seguintes modelos: (1) Modelo linear referente aos municípios tomados em conjunto; (2) Modelo linear referente aos municípios desenvolvidos; e (3) Modelo linear referente aos municípios não desenvolvidos. 
Tabela 3

Resultados das estimações lineares do modelo empírico

\begin{tabular}{|c|c|c|c|}
\hline & (1) & $(2)$ & (3) \\
\hline \multirow[t]{2}{*}{$G T_{i t} / P I B_{i t}$} & $-0,799 * * *$ & $-3,030 * * *$ & $-0,740^{* * *}$ \\
\hline & $(0,161)$ & $(0,359)$ & $(0,154)$ \\
\hline \multirow[t]{2}{*}{ legisl $_{i t}$} & $-0,139 *$ & $-0,974^{* * *}$ & $-0,115$ \\
\hline & $(0,0816)$ & $(0,337)$ & $(0,0835)$ \\
\hline \multirow[t]{2}{*}{$j u d_{i t}$} & $-0,223^{* * *}$ & $-0,212$ & $-0,227^{* * *}$ \\
\hline & $(0,0844)$ & $(0,309)$ & $(0,0874)$ \\
\hline \multirow[t]{2}{*}{ adm_plan $i t$} & $-0,0138$ & 0,0796 & $-0,0250$ \\
\hline & $(0,0299)$ & $(0,0841)$ & $(0,0319)$ \\
\hline \multirow{2}{*}{ agric $_{i t}$} & 0,0171 & 0,274 & 0,00773 \\
\hline & $(0,0561)$ & $(0,215)$ & $(0,0579)$ \\
\hline \multirow[t]{2}{*}{$e d u c_{-} c u l t_{i t}$} & 0,00218 & 0,0182 & 0,00306 \\
\hline & $(0,0316)$ & $(0,112)$ & $(0,0333)$ \\
\hline \multirow[t]{2}{*}{$h a b \_u r b_{i t}$} & $0,0612^{*}$ & $0,171^{* *}$ & 0,0598 \\
\hline & $(0,0356)$ & $(0,0863)$ & $(0,0376)$ \\
\hline \multirow[t]{2}{*}{ ind_com_serv $v_{i t}$} & 0,0184 & 0,312 & $-0,0114$ \\
\hline & $(0,100)$ & $(0,203)$ & $(0,110)$ \\
\hline \multirow[t]{2}{*}{ sau_san $_{i t}$} & $-0,0509^{*}$ & $-0,0292$ & $-0,0610^{*}$ \\
\hline & $(0,0297)$ & $(0,0956)$ & $(0,0314)$ \\
\hline \multirow[t]{2}{*}{ ass_prev $_{i t}$} & $-0,0305$ & $-0,184$ & $-0,0231$ \\
\hline & $(0,0457)$ & $(0,149)$ & $(0,0480)$ \\
\hline \multirow[t]{2}{*}{ trans $_{i t}$} & $0,0820^{* *}$ & 0,137 & $0,0738^{*}$ \\
\hline & $(0,0396)$ & $(0,0972)$ & $(0,0417)$ \\
\hline \multirow[t]{2}{*}{ seg_pub $_{i t}$} & $-0,226$ & $-0,00635$ & $-0,315$ \\
\hline & $(0,220)$ & $(0,458)$ & $(0,244)$ \\
\hline \multirow[t]{2}{*}{ energ $_{i t}$} & $-0,0428$ & $0,263^{* *}$ & $-0,0537$ \\
\hline & $(0,114)$ & $(0,113)$ & $(0,138)$ \\
\hline \multirow[t]{2}{*}{$\operatorname{com}_{i t}$} & $-0,400$ & $-0,846$ & $-0,284$ \\
\hline & $(0,309)$ & $(0,931)$ & $(0,323)$ \\
\hline \multirow[t]{2}{*}{ Constante } & $8,591^{* * *}$ & $9,536^{* * *}$ & $8,503^{* * *}$ \\
\hline & $(0,0299)$ & $(0,0513)$ & $(0,0311)$ \\
\hline Dummy de ano & Sim & Sim & Sim \\
\hline Observações & 58.677 & 5.627 & 53.050 \\
\hline Municípios & 5.533 & 489 & 5.044 \\
\hline R-Squared & 0,890 & 0,895 & 0,891 \\
\hline R2 - Overall & 0,328 & 0,506 & 0,332 \\
\hline
\end{tabular}

Fonte: Elaboração própria a partir dos dados do Tesouro Nacional e do IBGE. Erros padrões robustos entre parênteses. ${ }^{* * *} p<0.01,{ }^{* *} p<0.05,{ }^{*} p<0.1$

Nos modelos (1), (2) e (3), as estimações de $G T_{i t} / P I B_{i t}$ apresentaram valores negativos e estatisticamente significativos, revelando que, nos municípios tomados em conjunto ou classificados em desenvolvidos e não desenvolvidos, a produtividade dos gastos municipais foi menor do que o peso morto gerado pelo montante dos tributos necessários para financiá-los. Ademais, nos três modelos, todas as variáveis dummies de ano foram estatisticamente significantes, indicando que houve um fator comum explicando a taxa de crescimento dos municípios. Houve mudanças da classificação dos municípios em função das avaliações a cada ano do índice Firjan, mas não houve nenhum problema com 170 Revista Contabilidade Vista \& Revista, ISSN 0103-734X, Universidade Federal de Minas Gerais, Belo Horizonte, v. 32, n. 2, p. 152-183, maio/ago. 2021. 
outliers porque os dados e variáveis foram tratados, como por exemplo logaritmo neperiano e utilização dessas dummies de ano.

Similarmente aos resultados encontrados por Neduziak e Correia (2017) para os Estados, os gastos com a função legislativa apresentaram coeficientes negativos. Entretanto, apenas nos municípios tomados em conjunto (1) e nos classificados em desenvolvidos (2), apresentaram coeficientes significantes.

Os gastos com a função saúde e saneamento apresentaram coeficientes negativos nos três modelos, assim como nos resultados de Sousa e Paulo (2016) para os Estados. Entretanto, apenas nos modelos dos municípios tomados em conjunto e dos municípios não desenvolvidos, foram significativos.

Os resultados referentes aos gastos com saúde e saneamento nos municípios não desenvolvidos corroboram com o modelo teórico de Devarajan et al. (1996), visto que, nos países em desenvolvimento, gastos normalmente produtivos podem se tornar improdutivos se realizados em excesso.

Nos gastos com a função transporte, os três coeficientes foram positivos, do mesmo modo que os resultados encontrados por Rocha e Giuberti (2007) para os Estados. Entretanto, apenas nos modelos dos municípios tomados em conjunto e dos municípios não desenvolvidos, foram significativos. No gasto com segurança pública, observa-se que todos os coeficientes (dos três modelos) foram negativos e não significantes, assim como em Neduziak e Correia (2017).

Portanto, no modelo dos municípios tomados em conjunto (1), observa-se que os gastos com as funções legislativa, judiciária e saúde e saneamento afetaram negativamente a taxa de crescimento per capita, indicando que foram improdutivos. Por outro lado, os gastos com habitação e urbanismo e transportes afetaram positivamente, inferindo-se que foram produtivos.

No modelo dos municípios desenvolvidos (2), foram produtivos os gastos com habitação e urbanismo e energia, enquanto os gastos com a função legislativa foram improdutivos. Para os municípios não desenvolvidos (3), os gastos com as funções judiciária e saúde e saneamento afetaram negativamente a taxa de crescimento per capita, indicando que foram improdutivos. Por outro lado, diferentemente dos resultados de Devarajan et al. (1996), o gasto com a função transportes impactou positivamente, inferindo-se que foi produtivo. Um dos motivos é a diferença de amostras, pois Devarajan et al. (1996) estudaram 43 países em desenvolvimento por 20 anos, 1970 a 1990, enquanto o presente estudo analisou amostra de 5.533 municípios brasileiros de 2001 a 2016. Amostra de países é diferente e amostra dos municípios de somente um país, o que pode ser motivo de várias diferências nos resultados. Ademais, o período é um potencial motivo para diferenças entre os estudos. Enquanto até a década de 90 a o investimento rodoviário no Brasil foi predominante (Santos, 2002), a partir dos anos 2000 houve intensos investimentos no transporte aeréo, tanto de infraestrutura aeroportuária, quanto de investimento público-privado para viabilizar as vias aéreas (Silva \& Mourão, 2019). Além disso, nota-se que os resultados apresentados nos municípios não desenvolvidos (3) foram similares aos resultados do modelo estimado para toda a amostra (1), afinal, 91\% (5.044 do total de 5.533) dos municípios são classificados como não desenvolvidos pelo IFDM. 


\subsection{Estimações Quadráticas do Modelo Empírico}

Os resultados das estimações quadráticas do modelo empírico são apresentados na Tabela 4, apresentando os seguintes modelos: (1) Modelo quadrático referente aos municípios tomados em conjunto; (2) Modelo quadrático referente aos municípios desenvolvidos; e (3) Modelo quadrático referente aos municípios não desenvolvidos.

\section{Tabela 4}

Resultados das estimações quadráticas do modelo empírico

\begin{tabular}{|c|c|c|c|c|}
\hline & $\begin{array}{c}\text { (1) } \\
\text { Totalidade } \\
\end{array}$ & $\begin{array}{c}\text { (2) } \\
\text { Desenvolvidos } \\
\end{array}$ & $\begin{array}{c}\text { (3) } \\
\text { Desenvolvidos } \\
\end{array}$ & Não \\
\hline \multirow[t]{2}{*}{$G T_{i t} / P I B_{i t}$} & $-0,805^{* * *}$ & $-3,088^{* * *}$ & $-0,747^{* * *}$ & \\
\hline & $(0,164)$ & $(0,372)$ & $(0,157)$ & \\
\hline \multirow[t]{2}{*}{ legisl $_{i t}$} & $-0,0400$ & $2,712^{* * *}$ & $-0,0326$ & \\
\hline & $(0,132)$ & $(1,018)$ & $(0,126)$ & \\
\hline \multirow[t]{2}{*}{$j u d_{i t}$} & $-0,530 * * *$ & $-0,143$ & $-0,551^{* * *}$ & \\
\hline & $(0,168)$ & $(0,631)$ & $(0,173)$ & \\
\hline \multirow[t]{2}{*}{${a d m \_p l a n_{i t}}$} & $-0,00912$ & 0,203 & $-0,0358$ & \\
\hline & $(0,0707)$ & $(0,252)$ & $(0,0743)$ & \\
\hline \multirow[t]{2}{*}{$\operatorname{agric}_{i t}$} & $-0,00243$ & 0,515 & $-0,0116$ & \\
\hline & $(0,0836)$ & $(0,382)$ & $(0,0856)$ & \\
\hline \multirow[t]{2}{*}{$e d u c_{-} c u l t_{i t}$} & $-0,274^{* * *}$ & $-0,657$ & $-0,252^{* *}$ & \\
\hline & $(0,102)$ & $(0,555)$ & $(0,105)$ & \\
\hline \multirow[t]{2}{*}{$h a b_{-} u r b_{i t}$} & $-0,0481$ & 0,0166 & $-0,0523$ & \\
\hline & $(0,0663)$ & $(0,214)$ & $(0,0697)$ & \\
\hline \multirow[t]{2}{*}{ ind_com_serv $v_{i t}$} & 0,0879 & 0,369 & 0,0764 & \\
\hline & $(0,172)$ & $(0,364)$ & $(0,189)$ & \\
\hline \multirow[t]{2}{*}{$s a u_{-} s a n_{i t}$} & 0,105 & $0,456^{*}$ & 0,0723 & \\
\hline & $(0,0787)$ & $(0,267)$ & $(0,0819)$ & \\
\hline \multirow[t]{2}{*}{ ass_prev $_{i t}$} & $-0,0798$ & $-0,290$ & $-0,0792$ & \\
\hline & $(0,0979)$ & $(0,306)$ & $(0,103)$ & \\
\hline \multirow[t]{2}{*}{ trans $_{i t}$} & $0,156^{* *}$ & 0,103 & $0,153^{* *}$ & \\
\hline & $(0,0607)$ & $(0,219)$ & $(0,0630)$ & \\
\hline \multirow[t]{2}{*}{$\operatorname{seg}_{-} p u b_{i t}$} & $-0,132$ & 0,328 & $-0,324$ & \\
\hline & $(0,376)$ & $(0,742)$ & $(0,439)$ & \\
\hline \multirow[t]{2}{*}{$\operatorname{energ}_{i t}$} & 0,0756 & 0,383 & 0,157 & \\
\hline & $(0,150)$ & $(0,363)$ & $(0,216)$ & \\
\hline \multirow[t]{2}{*}{$\operatorname{com}_{i t}$} & $-0,379$ & $-1,876$ & $-0,164$ & \\
\hline & $(0,479)$ & $(2,300)$ & $(0,511)$ & \\
\hline \multirow[t]{2}{*}{ legisl $_{i t}{ }^{2}$} & $-0,535$ & $-67,27^{* * *}$ & $-0,214$ & \\
\hline & $(1,564)$ & $(18,85)$ & $(1,370)$ & \\
\hline \multirow[t]{2}{*}{$j u d_{i t}^{2}$} & $1,686^{* *}$ & 0,300 & $1,704^{* *}$ & \\
\hline & $(0,679)$ & $(3,103)$ & $(0,684)$ & \\
\hline \multirow[t]{2}{*}{ adm_plan ${ }_{i t}{ }^{2}$} & 0,0988 & $-0,275$ & 0,136 & \\
\hline & $(0,133)$ & $(0,592)$ & $(0,137)$ & \\
\hline \multirow[t]{2}{*}{$\operatorname{agric}_{i t}{ }^{2}$} & 0,424 & $-1,987$ & $0,456^{*}$ & \\
\hline & $(0,268)$ & $(1,840)$ & $(0,255)$ & \\
\hline \multirow[t]{2}{*}{ educ_cult $_{i t}{ }^{2}$} & $0,480^{* * *}$ & 0,991 & $0,462^{* * *}$ & \\
\hline & $(0,145)$ & $(0,960)$ & $(0,147)$ & \\
\hline
\end{tabular}




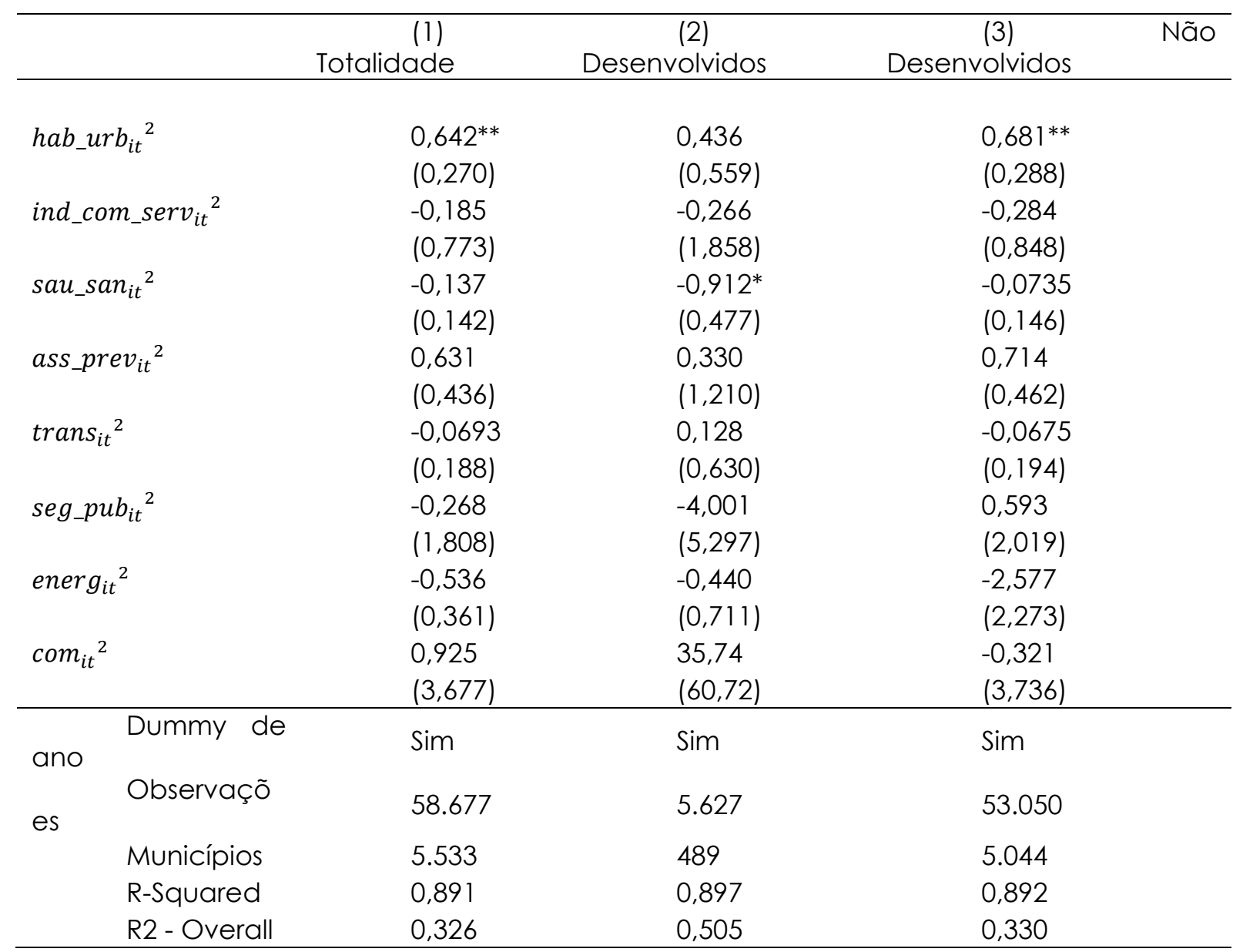

Fonte: Elaboração própria a partir dos dados do Tesouro Nacional e do IBGE. Erros padrões robustos entre parênteses. ${ }^{* * *} p<0.01,{ }^{* *} p<0.05,{ }^{*} p<0.1$

Observa-se que, novamente, os resultados apresentados nos municípios não desenvolvidos foram similares aos resultados do modelo estimado para toda a amostra. Nas especificações (1) e (3), a taxa de crescimento econômico se mostrou como uma função decrescente do gasto com a função judiciária e uma função crescente dessa variável ao quadrado, o que permite inferir uma relação não linear desse gasto com o crescimento econômico municipal.

O gasto com a função judiciária estava associado a um decréscimo na taxa de crescimento econômico, cujo limite ótimo, de acordo com os parâmetros estimados, seria de aproximadamente $16 \%$, tanto para os municípios tomados em conjunto, quanto para os municípios não desenvolvidos. Ou seja, de aproximadamente $16 \%$ em diante, praticamente, não existiriam mais retornos do aumento do gasto com a função judiciária sobre a taxa de crescimento do PIB per capita.

Ao analisar a média desse gasto em toda a amostra (Tabela 2), verificouse que, durante o período analisado, os valores alocados foram muito abaixo deste percentual. Diante disso, essa improdutividade poderia estar relacionada à insuficiente quantidade de recursos alocados. Contudo, gastos com a função judiciária são típicos dos Estados e da União, tendo em vista as características federativas brasileiras, dispostas na Constituição Federal (ver por exemplo, art. 92, 
art. 128, art. 132 e art. 134), o que justifica as pequenas proporções alocadas nos municípios.

Nas especificações (1) e (3), a taxa de crescimento econômico também se mostrou como uma função decrescente do gasto com a função educação e cultura e uma função crescente dessa variável ao quadrado. Assim, permite-se inferir uma relação não linear desse gasto com o crescimento econômico municipal, assim como em Rocha e Giuberti (2007).

Os gastos com a função educação e cultura estavam associados a um decréscimo na taxa de crescimento econômico. De acordo com os parâmetros estimados, o limite ótimo seria de aproximadamente $28 \%$, tanto para os municípios tomados em conjunto, quanto para os municípios não desenvolvidos.

Ao analisar a média desse gasto em toda a amostra (Tabela 2), notou-se que a proporção média, no período de 2001 a 2016, excedeu a esse limite ótimo nos municípios não desenvolvidos. Portanto, os resultados referentes aos gastos com educação e cultura nos municípios não desenvolvidos confirmam o modelo teórico de Devarajan et al. (1996), que demonstra que gastos aparentemente produtivos podem se tornar improdutivos se realizados em excesso.

Apenas nos municípios desenvolvidos, especificação (2), a taxa de crescimento econômico se mostrou como uma função crescente dos gastos com as funções legislativa e saúde e saneamento e uma função decrescente dessas variáveis ao quadrado, o que permite inferir uma relação não linear desses gastos com o crescimento econômico municipal. Por outro lado, os gastos com habitação e urbanismo e transportes afetaram positivamente o crescimento, inferindo-se que foram produtivos. Portanto, a grande contribuição é que os gastos que afetam negativamente podem ser excluídos ou reduzidos no âmbito das contas públicas, ou seja, os gastos considerados improdutivos. Essa constatação é relevante no âmbito de gestão de recursos públicos, os quais são limitados.

O gasto com a função legislativa estava associado a um acréscimo na taxa de crescimento econômico, cujo limite ótimo, de acordo com os parâmetros estimados, seria de aproximadamente $2 \%$, para os municípios desenvolvidos. Ou seja, de aproximadamente $2 \%$ em diante, praticamente, não existiriam mais retornos do aumento da razão entre gasto com a função legislativa e o gasto total sobre a taxa de crescimento do PIB per capita.

Ao analisar a média desse gasto em toda a amostra (Tabela 2), notou-se que a proporção média, no período de 2001 a 2016, excedeu a esse limite ótimo, nos municípios desenvolvidos, pois apresentou o valor médio de $2,75 \%$. Inferiu-se também uma relação não linear no gasto com a função saúde e saneamento, similarmente aos resultados encontrados por Sousa e Paulo (2016). Esse gasto estava associado a um acréscimo na taxa de crescimento econômico, cujo limite ótimo, de acordo com os parâmetros estimados, seria de aproximadamente $25 \%$, para os municípios desenvolvidos.

Ao analisar a média desse gasto em todo o período de 2001 a 2016 (Tabela 2), notou-se que a proporção média dos municípios desenvolvidos não excedeu a esse limite ótimo, apresentando um valor de $23,87 \%$. Os resultados referentes aos gastos com saúde e saneamento nos municípios desenvolvidos corroboram com Devarajan et al. (1996), os quais encontraram que em países em 
desenvolvimento gastos aparentemente produtivos podem se tornar improdutivos se realizados em excesso. Tal fato é observado no presente trabalho, pois seu coeficiente foi significante a $10 \%(-0,912 *)$. Portanto, respondendo-se o objetivo da pesquisa, a composição dos gastos públicos dos municípios brasileiros promove o crescimento econômico quando gastos de funções consideradas produtivas são realizados, como foi o caso das funções significativas apresentadas na Tabela 4, observados os grupos de municípios desenvolvidos e não desenvolvidos.

Resumidamente, alguns gastos são considerados produtivos, principalmente em função do objeto que se constitui com a realização do gasto (defesa pública é constituída com a realização do gasto com defesa, educação é constituída com a realização do gasto com defesa, assim por diante). Esses gastos devem ser priorizados na administração pública e os gastos considerados improdutivos devem sofrer cortes até evoluírem para serem finalmente retirados do orçamento governamental. Por fim, a análise por região (Norte, Nordeste, Centro-Oeste, Sudeste, Sul) não demonstrou diferenças significativas. Tal análise foi feita individualmente por região, pois a utilização de dummy não permitia avaliar as variáveis por problemas de colinearidade.

\section{CONCLUSÕES}

No atual contexto econômico do Brasil, é possível observar o desenvolvimento de um debate sobre os rumos e as propostas das políticas fiscais que promovam a solvência do setor público e a estabilidade da dívida pública. Este estudo propôs analisar como a composição dos gastos públicos dos municípios brasileiros, a partir da classificação funcional da despesa pública, promoveu crescimento econômico de longo prazo, considerando-se a classificação dos municípios em desenvolvido e não desenvolvido.

As estimações apresentaram valores negativos e estatisticamente significativos para o gasto total sobre o PIB, revelando que, nos municípios tomados em conjunto ou classificados em desenvolvidos e não desenvolvidos, a produtividade dos gastos municipais foi menor do que o peso morto gerado pelo montante dos tributos necessários para os financiar.

Em relação aos gastos improdutivos, ressalta-se que os resultados encontrados (nas estimações lineares e quadráticas) podem decorrer de características circunstanciais do período examinado, ou podem indicar a realidade brasileira de má alocação de recursos públicos.

No modelo dos municípios tomados em conjunto, os gastos com as funções legislativa, judiciária e saúde e saneamento afetaram negativamente a taxa de crescimento per capita, indicando que foram improdutivos. Por outro lado, os gastos com habitação e urbanismo e transportes afetaram positivamente, inferindo-se que foram produtivos. Portanto, a grande contribuição é que os gastos que afetam negativamente podem ser excluídos ou reduzidos no âmbito das contas públicas. Essa constatação é relevante no âmbito de gestão de recursos públicos, os quais são limitados.

No modelo dos municípios desenvolvidos, foram produtivos os gastos com habitação e urbanismo e energia e foram improdutivos os gastos com a função legislativa. Para os municípios não desenvolvidos, os gastos com as funções 
judiciária e saúde e saneamento afetaram negativamente a taxa de crescimento per capita, indicando que foram improdutivos. Enquanto, o gasto com a função transportes impactou positivamente, inferindo-se que foi produtivo.

Além disso, os resultados apresentados nos municípios não desenvolvidos foram similares aos resultados do modelo estimado para toda a amostra. Essa similaridade possivelmente decorre da composição da amostra: dos 5.533 municípios analisados, 5.044 são classificados como não desenvolvidos pelo IFDM. A decomposição da amostra dessa forma, pegando os municípios muito desenvolvidos, foi a intenção do estudo para testar se o modelo se diferenciava entre esses municípios muito desenvolvidos e os demais.

Como análise adicional, considerando uma relação teórica não-linear dos gastos públicos com o crescimento econômico, utilizou-se também uma especificação quadrática. Analisando todos os municípios da amostra e os não desenvolvidos, inferiu-se uma relação não linear dos gastos com funções judiciária e educação e cultura com o crescimento econômico. Nos municípios desenvolvidos, inferiu-se uma relação não linear dos gastos com funções legislativa e saúde e saneamento com o crescimento econômico.

Portanto, tanto nas estimações lineares, quanto nas quadráticas, os resultados desta pesquisa corroboram as evidências apontadas no estudo de Devarajan et al. (1996), visto que demonstram diferentes níveis de produtividade dos gastos públicos entre os municípios desenvolvidos e não desenvolvidos. Assim, os resultados foram coerentes com o estudo desses autores para os países. Diante desses resultados, é necessária recomposição dos gastos públicos municipais brasileiros com o objetivo de alcançar uma maximização da contribuição de cada gasto no crescimento econômico nacional. Pesquisadores futuros podem realizar estudos propondo modelos que viabilizam essa análise.

Ressalta-se que, ao integrar informações contábeis sobre os gastos públicos, a partir da classificação funcional da despesa pública, com o desempenho econômico, medido pelo agregado macroeconômico do Produto Interno Bruto (PIB) per capita, essa pesquisa relacionou a Contabilidade com a Economia, permitindo um exame e um debate otimizado da finança pública municipal brasileira.

Contudo, o enfoque se relacionou precipuamente ao potencial informacional dos dados contábeis públicos, nas finanças públicas. Portanto, não se evidenciaram razões e consequências estimuladoras (ou inibidoras) do gasto público agregado sobre o crescimento econômico.

Quanto ao escopo e à qualidade, destaca-se a limitação da disponibilidade dos dados e da utilização de um modelo teórico, como forma de simplificação de uma realidade complexa. A suposição de que não há relação de casualidade entre a variável dependente e as variáveis do gasto público, por exemplo, configura-se como uma limitação. Portanto, restringem-se os resultados e as conclusões deste estudo ao recorte do cenário de análise.

Ressalte-se também que os resultados se referem ao conjunto dos governos municipais, apenas classificados em desenvolvidos e não desenvolvidos, logo, não se aplicam para casos individuais. Além disso, possivelmente houve influência da relevância de determinados municípios na composição das variáveis estudadas. 
Apesar dessas limitações, considera-se que os resultados sejam robustos, haja vista a coerência dos procedimentos adotados aos estudos precursores, adequando os procedimentos metodológicos aos arcabouços teórico e empírico já consagrados na literatura.

Para futuras pesquisas, sugere-se identificar as razões dos resultados encontrados nesse estudo quanto à identificação da composição do gasto público municipal e quanto à relação da composição e do crescimento econômico; investigar outros períodos, tentando capturar, por exemplo, efeitos de crises; investigar a composição do gasto municipal considerando uma classificação mais detalhada dos municípios (não apenas, em desenvolvidos e não desenvolvidos) e/ou aprofundando o debate sobre o federalismo fiscal na análise dos resultados da relação entre gasto público municipal e crescimento econômico, tendo em vista a heterogeneidade dos municípios brasileiros; investigar outros fatores impactantes nas escolhas da formatação de gastos públicos, que podem influenciar na relação entre composição do gasto público e crescimento econômico, tais como escolaridade, natalidade, mortalidade, taxa de desemprego e expectativa de vida; e investigar a produtividade dos gastos municipais, considerando aspectos ambientais (exploração de recursos naturais), aspectos regionais, aspectos de desenvolvimento humano, entre outros.

\section{REFERÊNCIAS}

Araújo, Jair Andrade de, Monteiro, Vitor Broges \& Cavalcante, Cristina Aragão. (2010). A Influência dos gastos públicos no crescimento econômico dos Municípios do Ceará. Instituto de Pesquisa e Estratégia do Ceará - IPECE, Fortaleza.

Arraes, Ronaldo. A. \& Teles, Vladimir. K. (2001). Política fiscal e crescimento econômico: aspectos teóricos e evidências empíricas para as regiões brasileiras. Revista Econômica do Nordeste, 32, n. Especial.

Aschaver, David Alan. (1989). Is public expenditure productive? Journal of monetary economics, v. 23, n. 2, p. 177-200. http://dx.doi.org/10.1016/0304$\underline{3932(89) 90047-0}$

Barro, Robert J. (1991). Economic growth in a cross section of countries. The quarterly journal of economics, 106(2), 407-443. http://dx.doi.org/10.2307/2937943

Barro, Robert J. (1990). Government spending in a simple model of endogeneous growth. Journal of political economy, 98(5), Part 2, S103-S125. http://dx.doi.org/10.1086/261726

Baynaktar, Nihal \& Moreno-Dodson, Blanca. (2010). How can public spending help you grow? An empirical analysis for developing countries. The World Bank. http://dx.doi.org/10.1596/1813-9450-5367

Bleaney, Michael, Gemmell, Norman \& Kneller, Richard. (2001). Testing the endogenous growth model: public expenditure, taxation, and growth over the 
long run. Canadian Journal of Economics/Revue canadienne d'économique, 34(1), 36-57. http://dx.doi.org/10.11111/0008-4085.00061

Bogoni, Nadia Mar, Hein, Nelson \& Beuren, Ilse Maria. (2011). Análise da relação entre crescimento econômico e gastos públicos nas maiores cidades da região Sul do Brasil. Revista de administração pública, 45(1), 159-179. http://dx.doi.org/10.1590/S0034-76122011000100008

Bose, Niloy, Haque, M. Emranul \& Osborn, Denise R. (2007). Public expenditure and economic growth: A disaggregated analysis for developing countries. The Manchester School, 75(5), 533-556. http://dx.doi.org/10.1111/j.14679957.2007.01028.x

Campo, Jacobo \& Mendoza, Henry. (2018). Gasto público y crecimiento económico: un análisis regional para Colombia, 1984-2012. Lecturas de Economía, 88, 77-108. http://www.scielo.org.co/pdf/le/n88/0120-2596-le-8800077.pdf

Cândido Júnior, José O. (2001). Os gastos públicos no Brasil são produtivos? Brasília: IPEA, fev. (Texto para discussão n. 781). http://ipea.gov.br/agencia/images/stories/PDFs/TDs/td 0781.pdf

Carboni, Oliviero A. \& Medda, Giuseppe. (2011). Size and composition of public spending in a neoclassical growth model. Metroeconomica, 62(1), 150-170. http://dx.doi.org/10.1111/j.1467-999X.2010.04093.x

Cardoso, Vanessa R. dos Santos, Pansani, Daniel A., Serrano, André Luiz M. \& Wilbert Marcelo D. (2018). Sustentabilidade da dívida pública: uma análise de curto e longo prazo aplicada aos municípios agregados. Revista Universo Contábil, 14(3), 07-27, jul./set. http://dx.doi.org/10.4270/RUC.2018317

Cashin, P. (1995). Government Spending, Taxes and Economic Growth. IMF Staff Papers, 42(2), 237-269.

Cavallo, Eduardo \& Daude, Christian. (2008). Public investment in developing countries: A blessing or a curse? Journal of Comparative Economics, 39(1), p. 65-81. http://dx.doi.org/ 10.2139/ssrn.1820935

Degenhart, Larissa et al. (2016). Relação entre crescimento econômico e gastos públicos dos municípios da região norte do Brasil. Revista Eletrônica de $\begin{array}{lll}\text { Administração e } \quad \text { Turismo-ReAT, } & \text { 1050-1072. }\end{array}$ http://dx.doi.org/10.15210/REAT.V915.7487

Devarajan, Shantayan, Swarrop, Vinaya \& Zou, Heng-fu. (1996). The composition of public expenditure and economic growth. Journal of Monetary Economics, 37(2), 313-344. http://dx.doi.org/10.1016/S0304-3932(96)90039-2

Divino, José Angelo \& Silva Junior, Rogério Lúcio Soares da. (2012). Composição dos gastos públicos e crescimento econômico dos municípios brasileiros. 
Revista

Economia

http://www.anpec.org.br/revista/vol13/vol13n3ap507 528.pdf

Domar, E. (1946). Capital Expansion, Rate of Growth, and Employment. Econometrica, 14(2), 137-147. http://dx.doi.org/10.2307/1905364

Farrel, M. J. (1957). A measurement of productive efficiency. Journal of The Royal Statistical Society, 120, 254-290. http://dx.doi.org/10.2307/2343100

Fernandes, José Lúcio Tozetti. (2016). Maldição dos recursos naturais e produtividade do gasto público nos municípios brasileiros. Tese (Doutorado em Ciências Contábeis) - Programa Multi-institucional e Inter-Regional de PósGraduação em Ciências Contábeis UnB/UFPB/UFRN, Universidade de Brasília, Brasília. https://repositorio.unb.br/handle/10482/20170

Fournier, Jean-Marc \& Johansson, Asa. (2016). The effect of the size and the mix of public spending on growth and inequality. OECD Publishing, 1344. http://dx.doi.org/10.1787/f99f6b36-en

Ghosh, Sugata \& Gregoriou, Andros. (2008). The composition of government spending and growth: is current or capital spending better? Oxford Economic Papers, 60(3), 484-516. http://dx.doi.org/10.1093/oep/gpn005

Giambiagi, Fabio \& Sidone, Otávio José Guerci. (2018). A reforma previdenciária e o teto do Regime Geral de Previdência Social (RGPS). Rio de Janeiro: Banco Nacional de Desenvolvimento Econômico e Social.

Giuberti, Ana Carolina \& Rocha, Fabiana. (2015). Composição ótima do gasto público para o crescimento econômico. In: Boveri, Rogério; Rocha, Fabiana; Rodopoulos, Fabiana (Organizadores). Avaliação da qualidade do gasto público e mensuração da eficiência. Brasília: Secretaria do Tesouro Nacional.

Gramlich, Edward M. (1994). Infrastructure investment: A review essay. Journal of economic literature, 32(3), 1176-1196.

Harrod, R. (1972). An Essay in Dynamic Theory. In: Economic Essays. Palgrave Macmillan, London.

Herrera, Santiago \& Blanco, Fernando. (2004). The quality of fiscal adjustment and the long run growth impact of fiscal policy in Brazil. Draft paper, World Bank. http://hdl.handle.net/10986/9299

Heintz, James. (2010). The impact of public capital on the US private economy: new evidence and analysis. International Review of Applied Economics, 24(5), 619-632. http://dx.doi.org/10.1080/02692170903426104

Johansson, Åsa. (2016). Public Finance, Economic Growth and Inequality. OECD Economic Department Working Papers. OECD Publishing, 1346. https://www.oecd.org/economy/public-finance/Public-finance-economicgrowth-and-inequality-a-survey-of-the-evidence.pdf 
Kneller, Richard, Bleaney, Michael F. \& Gemmell, Norman. (1999). Fiscal policy and growth: evidence from OECD countries. Journal of Public Economics, 74(2), 171-190. http://dx.doi.org/10.1016/S0047-2727(99)00022-5

Kneller, Richard \& Misch, Florian. (2014). The effects of public spending composition on firm productivity. Economic Inquiry, 52(4), 1525-1542. http://dx.doi.org/10.1111/ecin.12092

Lovell, C. A. K. (1993). Production frontiers and productive efficiency. In: The measurement of productive efficiency: techniques and applications. New York: Oxford University Press, 3-67.

Lupu, D., Petrisor, M. B., Bercu, A. \& Tofan, M. (2018). The Impact of Public Expenditures on Economic Growth: A Case Study of Central and Eastern European Countries. Emerging Markets Finance and trade, 54(3), 552-570. http://dx.doi.org/10.1080/1540496X.2017.1419127

Macedo, J. J. \& Corbari, E. C. (2009). Efeitos da Lei de Responsabilidade Fiscal no endividamento dos municípios brasileiros: uma análise de dados em painéis. Revista Contabilidade \& Finanças, 20(51), 44-60, set./dez. http://dx.doi.org/10.1590/S1519-70772009000300004

Maciel, A. P. B.; Alarcon, A. O. \& Gimenes, É. R. (2018). Partidos políticos e espectro ideológico: Parlamentares, especialistas, esquerda e direita no Brasil. Revista $\begin{array}{llll}\text { Eletrônica de Ciência } & \text { 72-88. }\end{array}$ http://dx.doi.org/10.5380/recp.v8i3.54834

Makuyana, Garikai \& Odhiambo, Nicholas M. (2017). Public and private investment and economic growth in Zimbabwe: An empirical test. Business and Economic Horizons, 13(1), 60-76. http://dx.doi.org/10.22004/ag.econ.264626

Miller, Stephen M. \& Russek, Frank S. (1997). Fiscal structures and economic growth: international evidence. Economic Inquiry, 35(3), 603-613. http://dx.doi.org/10.1111/j.1465-7295.1997.tb02036.x

Moreno-Dodson, Blanca. (2008). Assessing the Impact of Public Spending on Growth: An Empirical Analysis for Seven Fast Growing Countries. Policy Research Working Paper, 4663. http://hdl.handle.net/10986/6850

Moreno-Dodson, Blanca \& Baynaktar, Nihal. (2011). How Public Spending Can Help You Grow: An Empirical Analysis for Developing Countries. World BankEconomic Premise, 48, 1-4. http://hdl.handle.net/10986/10107

Neduziak, Luiz Carlos Ribeiro \& Correia, Fernando Motta. (2017). Alocação dos gastos públicos e crescimento econômico: um estudo em painel para os estados brasileiros. Revista de Administração Pública, 51(4), 616-632. http://dx.doi.org/10.1590/0034-7612155177 
Ntembe, Augustin, Amin, Aloysius Ajab \& Tawah, Regina. (2017). Analysis of public investments and economic growth in Cameroon. Journal of Economics and Finance, 42(3), 591-614. http://dx.doi.org/10.1007/s12197-017-9411-0

Ogundipe, Adeyemi A. \& Oluwatobi, Stephen. (2013). Government spending and economic growth in Nigeria: Evidence from disaggregated analysis. Journal of Business Management and Applied Economics, 2(4), 1-10. http://dx.doi.org/10.9734/air/2019/v19i430128

Piccoli, Marcio Roberto, Baronchello, Débora \& Nardi, Janini. (2017). A importância do gasto público no crescimento econômico municipal. Revista de Administração e Contabilidade-RAC (CNEC), 16(32). https://core.ac.uk/reader/229768530

Ram, Rami. (1986). Government size and economic growth: a new framework and some evidence from cross-section and time-series data. The American Economic Review, 76(1), 191-203. http://dx.doi.org/10.1007/BF00204946

Rezende, Fernando. (2010). Finanças públicas. São Paulo: Atlas.

Rocha, F. \& Giuberti, A. C. (2007). Composição do gasto público e crescimento econômico: uma avaliação macroeconômica da qualidade dos gastos dos estados brasileiros. Economia Aplicada, 11(4), 463-485. http://dx.doi.org/10.1590/S1413-80502007000400001

Rodrigues, Rodrigo Vilela \& Teixeira, Erly Cardoso. (2010). Gasto público e crescimento econômico no Brasil: uma análise comparativa dos gastos das esferas de governo. Revista Brasileira de Economia, 64(4), 423-438. http://dx.doi.org/10.1590/S0034-71402010000400005

Santos, João Almeida. (2002). História do transporte rodoviário. Revista lbero Americana de Estratégia, 1(1), 27-32. http://www.spell.org.br/documentos/ver/26647/historia-do-transporterodoviario/i/pt-br

Schumpeter, Joseph A. (1961). The Theory of Economic Development. Oxford: Oxford University Press, 1961.

Silva, Gabriela Aguiar da \& Mourão, Gustavo Nunes. (2019). Concentração no mercado de transporte aéreo de passageiros no brasil: uma avaliação do período 2000-2017. Caderno PAIC, 20(1), 97-116. https://cadernopaic.fae.edu/cadernopaic/article/view/346

Silva, Guilherme Jonas Costa \& Santolin, Roberto Salvador. (2012). Gastos públicos e crescimento econômico recente dos estados brasileiros. Revista Economia \& Tecnologia, 8(3). http://dx.doi.org/10.5380/ret.v8i3.29870

Sousa, Rossana Guerra \& Paulo, Edilson. (2016). Produtividade dos Gastos Públicos dos Estados Brasileiros. Um Estudo Empírico no Período de 1995 a 2010. 
Desenvolvimento em Questão, 14(36). http://dx.doi.org/10.21527/2237$\underline{6453.2016 .36 .187-219}$

Souza, G. S. de. (2007). Política fiscal e crescimento econômico: evidências para o caso brasileiro. Dissertação (Mestrado em Economia) - Departamento de Economia da Faculdade de Economia, Administração e Contabilidade de Ribeirão Preto da Universidade de São Paulo (FEA-RP/USP), Universidade de São Paulo, Ribeirão Preto. http://dx.doi.org/10.1 1606/D.96.2007.tde-25072007083907

Souza, G. S. de., Kannebley JR., S. \& Diniz, E. M. (2010). Política fiscal e crescimento de longo prazo no Brasil: evidências para dados do orçamento função. Pesquisa e Planejamento Econômico, 40(1), 41-84, abr. http://repositorio.ipea.gov.br/handle/11058/5103

Tarouco, G. da S. \& Madeira, R. M. (2013). Partidos, programas e o debate sobre esquerda e direita no Brasil. Revista de Sociologia e Política, 21 (45), 149-165. http://dx.doi.org/10.1590/s0104-44782013000100011

Yilmaz, G. (2018). Composition of public investment and economic growth: evidence from Turkish provinces, 1975-2001. Public Sector Economics, 42(2), 187-214. http://dx.doi.org/10.3326/pse.42.2.10 


\section{CONTRIBUIÇÕES DOS AUTORES}

\begin{tabular}{|c|c|c|c|}
\hline Contribuição & $\begin{array}{l}\text { André Luiz } \\
\text { Marques } \\
\text { Serrano }\end{array}$ & $\begin{array}{l}\text { Layane } \\
\text { Gonçalves } \\
\text { Furtado }\end{array}$ & $\begin{array}{l}\text { Lucas Oliveira } \\
\text { Gomes Ferreira }\end{array}$ \\
\hline $\begin{array}{l}\text { 1. Idealização e concepção do assunto } \\
\text { e tema da pesquisa }\end{array}$ & $\checkmark$ & $\checkmark$ & \\
\hline 2. Definição do problema de pesquisa & $\checkmark$ & & \\
\hline $\begin{array}{l}\text { 3. Desenvolvimento da Plataforma } \\
\text { Teórica }\end{array}$ & & $\checkmark$ & $\checkmark$ \\
\hline $\begin{array}{l}\text { 4. Delineamento da abordagem } \\
\text { metodológica da pesquisa }\end{array}$ & $\checkmark$ & & \\
\hline 5. Coleta de dados & & $\checkmark$ & $\checkmark$ \\
\hline $\begin{array}{l}\text { 6. Análises e interpretações dos dados } \\
\text { coletados }\end{array}$ & & & $\checkmark$ \\
\hline 7. Conclusões da pesquisa & & & $\checkmark$ \\
\hline 8. Revisão crítica do manuscrito & $\checkmark$ & & \\
\hline $\begin{array}{l}\text { 9. Redação final do manuscrito, } \\
\text { conforme as normas estabelecidas pela } \\
\text { Revista. }\end{array}$ & & & $\checkmark$ \\
\hline 10. Orientação & $\checkmark$ & & \\
\hline
\end{tabular}

